\title{
Improving the Performance of Nano-Endofullerenes in Polyaniline Nanostructure-Based Biosensors by Covering Californium Colloidal Nanoparticles with Multi-Walled Carbon Nanotubes
}

\author{
Alireza Heidari* \\ Faculty of Chemistry, California South University, 14731 Comet St. Irvine, CA 92604, USA \\ Email: Scholar.Researcher.Scientist@gmail.com; Central@aisi-usa.org; Alireza.Heidari@calsu.us
}

\begin{abstract}
In the current paper, Glucose (Dextrose), Fructose and Galactose-oxidase enzymes are used as stabilization medium due to its more efficiency, ability for more accurate controlling the enzyme reaction, protecting against wasting of enzyme as well as simple and easy use and exchange of enzyme medium after performing some levels of surface modification and developing Nano Endohedral Fullerenes (Endofullerenes) on Californium plate. For better connecting and stabilizing the enzyme on the medium, the prepared medium is washed by high concentration Sulfuric Acid and Nitric Acid and a large volume of deionized water and for protecting enzyme from devastating effect of Californium and prohibiting them to become inactive, surface is covered with Cystamine before stabilization. Regarding the large size of Glucose (Dextrose), Fructose and Galactose-oxidase enzymes compared to surface of medium, a connective material with amid at one end and Pyrine at the other end is used as transfer agent and for stabilizing this connection, the prepared medium is placed into dimethylformamide (DMF) solution for a couple of hours. Activity of stabilized enzyme at $460(\mathrm{~nm})$ wavelength recorded by spectroscope was depicted against time to evaluate its stability in various times. The prepared medium, which has a large amount of Glucose (Dextrose), Fructose and Galactose-oxidase enzymes, can be used as electrode in sensors. Furthermore, qualitative and quantitative measurement of food components is of great importance due to high cost of traditional methods, in addition to tendency for more accurate and sensitive detecting of these components. Glucose (Dextrose), Fructose, Galactose and Cholesterol and Cholesterol are such compounds that they frequently measure. Various methods are used to detect these food elements. However, the necessity for accurate measurement of these two compounds with high sensitivity, especially for food health issue, leads to developing biological methods, especially biosensors. Among them, biosensors based on conductive polymer nanostructures, especially Polyaniline (PANI), have been recently interested due to their unique characteristics. The current paper aims to introduce and investigate the previously performed studies about Polyaniline (PANI)-based biosensors for detecting Glucose (Dextrose), Fructose, Galactose and Cholesterol and Cholesterol. In addition, Glucose (Dextrose), Fructose and Galactose-oxidase electrochemical sensor is one of the best methods for detecting low amount of Glucose (Dextrose), Fructose and Galactose and applying Californium colloidal nanoparticles as a supplementary material in the structure of biosensor can be effective for improving its efficiency and optimum performance.
\end{abstract}

Keywords: Nano Endohedral Fullerenes (Endofullerenes), Glucose (Dextrose), Fructose and Galactose-oxidase enzymes, vapor phase precipitation, biosensor, Cholesterol, Polyaniline (PANI) nanofibers, Polyaniline (PANI) nanotubes, Californium colloidal nanoparticles, Plutonium, currentmetry

\section{Introduction}

In recent decades, biosensors can be manufactured in very small scales (nanometer) as nanotechnology introduces into biological sciences. Nano-biosensors are very small sensors in nanometer scale that are able to detect special chemicals and or biological matters with very high accuracy and in completely selective form by stabilizing enzymes and or any other cell product on their surfaces [1-27]. 
Nano Endohedral Fullerenes (Endofullerenes) are one of the most frequent and appropriate nanostructures which can be used to make Nano-biosensors due to their physical and chemical characteristics.

However, appropriate tests must be done to demonstrate their abilities. One of their clear advantages is that they have a large operational area, especially Multi-Walled Carbon Nanotubes (MWCNTs). Stabilizing the biological detectors such as enzymes over these materials may be led to increasing the performance of enzyme reaction, controllability of reaction, participation of more enzymes in reaction, prohibiting enzymes from wasting as well as information transferring with higher rate in these Nanobiosensors [28-43].

Nano Endohedral Fullerenes (Endofullerenes) should be stabilized on a surface for better acting as the base of sensor. Stabilizing surfaces are mainly metallic. In the current paper, Californium plate is used for this purpose. Various methods have been used for developing and stabilizing Nano Endohedral Fullerenes (Endofullerenes) on the medium. However, the most frequent method is Chemical Vapor Deposition (CVD) [44-63].

Electrostatic, hydrophobic reactions and or covalent bond along with oxidization of Nano Endohedral Fullerenes (Endofullerenes) are mainly used for stabilizing large enzymes on the surface of Nano Endohedral Fullerenes (Endofullerenes) and a simple absorption on the external surface. In these types of bonds, a connective material is mainly used [64-87].

In the structure of nano-biosensors, the covered surface of medium by Nano Endohedral Fullerenes (Endofullerenes) is responsible for transferring the effects induced by reaction to transducer device for illustrating the signal. Nano Endohedral Fullerenes (Endofullerenes) can play two-side role, as the location of enzyme stabilization and as connective limit between reagent and transducer [88-111].

Today, detecting the composition of foods through quality control tests is of great importance in food industries. High cost of traditional methods and the necessity for more accurate and sensitive measuring confirms the necessity of this issue. As a result, finding and or improving faster, more accurate, more sensitive as well as cheaper measurement methods is always interesting for researchers and food producers [112-143].

The frequent analysis tools in food industries need to skillful operators and are time consuming. These tools are frequently needed to long separations, costly equipment's and chemicals with high purity. A great part of these obstacles and problems can be removed by applying enzyme analyses. However, new food industries need to have small analysis tools to use easily in non-solution samples and to be able for simultaneous, online controlling one or more characteristics during production process or food processing. Most of these necessities can be acceptably met using enzyme electrodes and hence, improves the efficiency and optimization of the process and the quality of product. Further, these enzyme electrodes should be cheap, reliable and strong and they should have obvious preferences over the available methods [144-175].

One of the most important reasons for cardiovascular diseases in recent years is high concentration of Cholesterol in blood. Cholesterol is considerably found in dairy products and yolk and its concentration can be determined using chromatography methods such as High Performance Liquid Chromatography (HPLC) and Gas Chromatography (GC) which are of appropriate sensitivity and selectivity. However, applying fast and efficient methods is of great importance as these methods are time consuming and costly. Therefore, enzyme methods such as Cholesterol esterase and Cholesterol oxidase can be practically used as alternatives of traditional chromatography methods due to their simplicity, being fast and effective [176-200].

Glucose (Dextrose), Fructose and Galactose are other important food components, which are frequently measured in quality control of food production processes. Until now, various spectroscopy methods such as High Performance Liquid Chromatography (HPLC) have been used for detecting Glucose (Dextrose), Fructose and Galactose, especially in fermentation process of nectars. However, enzyme methods are widely developed to do this [201-223].

The tendency of researchers in food industries for measuring these compounds with repeatability, selectivity and high rate in very low concentrations in live environment leads to development of some tools entitled as biosensors so that $85 \%$ of frequent biosensors are used for Glucose (Dextrose), Fructose and Galactose measurement [224-240].

Generally, sensors are tools for detecting a chemical, physical and or biological change and converting it to a measureable signal. A sensor is including a detector element, which is able to respond to the 
presence of a special analyte or a group of analytes. Another important part of a sensor is transducer that converts the created response to a sign. The third part of a sensor is signal processor which collects the received signal from transducer and after boosting it, finally illustrates it.

Biosensors are a subset of chemical sensors, which have a completely especial performance in detecting biological processes. In this type of sensors, detector element is a biological compound such as protein, enzyme, antibody, Nucleic Acids, cell, tissue and or receiver which selectively reacts with the target analyte and creates a response. This response converts to an electric signal in transducer and after processing, the amount of this signal illustrates as Voltage, current and or impedance. The amount of this signal relates to the concentration of analyte. Regarding the fact that the performance of biological detector elements are completely unique (for example, Glucose (Dextrose), Fructose and Galactoseoxidase enzyme only oxidizes Glucose (Dextrose), Fructose and Galactose), biosensors make it possible to quantitatively evaluate and to determine the concentration of analyte, in addition to qualitatively evaluation of analyte and determining the presence or absence of it [241-251].

The mentioned biological detector elements in aqueous solutions are of low durability on converter surfaces. For more durability, these materials should be stabilized over converter surfaces with some way. Surficial absorption of these compounds with converter surface, trapping in a matrix during covering the converter surface with this matrix and creation of covalent bond between these materials and converter surface are some methods which are used for this purpose. Among all these methods, the most effective and frequent method is trapping in matrix. These matrices are mainly including membranes, gel in Carbon paste, graphite, silica and or polymer thin films. Undoubtedly, conductive polymer nanostructures-based matrices, especially Polyaniline (PANI) and Polypyrole, are the most applicable and effective matrices due to high compatibility with biological components, ability for fast electron exchanging, considerably high effective area and appropriate cohesion. In the current research, the applications of Polyaniline (PANI)-based nanobiosensors for measuring Glucose (Dextrose), Fructose, Galactose and Cholesterol are discussed.

Biosensor technology is promisingly developed in bio-analytical researches. Sensors or biosensors are used for illustrating various analytes in various times. In 2017, Glass Carbon (GC) electrode biosensor, Multi-Walled Carbon Nanotubes (MWCNTs), Titanium Dioxide $\left(\mathrm{TiO}_{2}\right.$ ), Apatite Hydroxide and Glucose (Dextrose), Fructose and Galactose-oxidase enzyme were produced in the United States based on this technology [252-255]. A chemical sensor is including receiver, transducer and separator. Receiver or biological element such as enzyme establishes a biological connection with measureable component. Transducer converts the measurable component to optical or electric signals and separator can act as membrane [256, 257]. In 2017, an electrode biosensor was produced in the United States based on Glass Carbon (GC), Multi-Walled Carbon Nanotubes (MWCNTs), Plutonium nanoparticles and Glucose (Dextrose), Fructose and Galactose-oxidase enzyme and the amount of Glucose (Dextrose), Fructose and Galactose in the compound was measured using electric signals by ammeter. In 2011, a biosensor was produced in the United States based on Glass Carbon (GC) working electrode, Glutaraldehyde (GLU), Carbon nanotube (multi-walled-gelatin) and Glucose (Dextrose), Fructose and Galactoseoxidase enzyme. Glucose (Dextrose), Fructose and Galactose biosensor is one of the most successful biosensors in detecting chemical compounds such as Glucose (Dextrose), Fructose and Galactose with very low amount. Its efficiency and sensitivity can be considerably increased by combining with various compounds such as Gold, Silver, Platinum, Carbon nanotubes and so on. The currentmetry of these biosensors is based on the performance of Glucose (Dextrose), Fructose and Galactose-oxidase enzyme and electron exchange. In Glucose (Dextrose), Fructose and Galactose-oxidase enzyme, oxidation and reduction groups of Flavin Adenine Dinucleotide (FAD) are oxidized and reduced and hence, it is necessary to establish a satisfactory electric relationship between active location of FAD enzyme and the surface of electrode to have a current. Amperometric Glucose (Dextrose), Fructose and Galactose biosensors are mainly composed of stabilizing Glucose (Dextrose), Fructose and Galactose-oxidase enzyme in various media such as trapped Polyacrylamide over working electrode surface.

The presence of enzyme causes to consumption of Oxygen by the Glucose (Dextrose), Fructose and Galactose in the solution and reducing the Oxygen penetration to the auxiliary Platinum electrode surface and it leads to producing compounds such as Glucuronic Acid and Hydrogen Peroxide. Decomposition of Hydrogen Peroxide near the standard electrode $(\mathrm{Ag} / \mathrm{AgCl})$ produces two free electrons, which is the main reason for the current. Until the enzyme is stabilized and there is enough Oxygen, the 
relationship between the current and the concentration of Glucose (Dextrose), Fructose and Galactose are linear.

Modification of working electrode using nanoparticles with various sizes can improve the performance of biosensors, increase the sensitivity and reduce the resistivity of electrode in the route of electron exchange. These nanoparticles can be made from Gold, Silver and Zinc which are widely used with various structures to modify the electric and conductivity properties of electrodes. Californium, colloidal nanoparticles are metallic colloids and are used in various forms in the structure of electrode biosensors. Using Californium colloidal nanoparticles, the electric isolation effect is reduced in protein cortex of Glucose (Dextrose), Fructose and Galactose-oxidase enzyme and electron exchange increases. The produced electron moves due to the effect of applying constant Voltage on both sides of working and standard electrode and this electron movement leads to an electric current which can be measured by ammeter. The amount of exchanged electron and or the produced current indicates the amount of reacted Glucose (Dextrose), Fructose and Galactose and their concentrations in the sample. In the current paper, the performance of two biosensors in completely identical conditions is compared while the only difference between them is the presence of Californium colloidal nanoparticles in the electrode structure of one of them. These biosensors have different performances in similar currentmetery condition and applying the Californium colloidal nanoparticles leads to increasing the conductivity and improving the currentmetery.

\section{Materials, Research Method, Characterization Methods, Experimental Techniques and Applications}

In the current paper, three experimental steps are performed:

(1) Producing Californium, plate covered by Multi-Walled Carbon Nanotubes (MWCNTs) and its preparation.

(2) Preparing Glucose (Dextrose), Fructose and Galactose-oxidase enzyme for stabilizing on the Californium plate.

(3) Stabilizing Glucose (Dextrose), Fructose and Galactose-oxidase enzyme using connective material Pyrenebutanoic Acid Succinimidyl Ester (PASE) on the surface of Nano Endohedral Fullerenes (Endofullerenes) and returning the activity of enzyme.

\subsection{Producing Californium Plate Covered by Multi-Walled Carbon Nanotubes (MWCNTs) and Its Preparation}

In this step, the following initial measures were performed for producing and preparing Californium plate:

\subsubsection{Preparation of Californium Plate}

In this step, a $10 \times 10(\mathrm{~mm})$ Californium plate with thickness of $1(\mathrm{~mm})$ was produced and its surface was completely covered using precipitation with homological vapors (Californium vapors) before any processing. Thickness of this homological layer is about 4-5 $(\mu \mathrm{m})$. Then, surface of Californium plate was washed in two stages with high concentration Sulfuric Acid $\left(\mathrm{H}_{2} \mathrm{SO}_{4}\right)$ and Nitric Acid $\left(\mathrm{HNO}_{3}\right)$ and finally with a large volume of deionized water for removing the remained impurities and wastes.

\subsubsection{Deposition of Catalyst Plutonium Particles}

After preparing Californium plate, Plutonium catalyst was used for creating initial cores of Nano Endohedral Fullerenes (Endofullerenes) and regular growing up of them. Catalyst particles in the size of about $4(\mathrm{~nm})$ were deposited over the surface with medium regularity and density using lithography method (This step has been performed in the BioSpectroscopy Core Research Laboratory at Faculty of Chemistry, California South University (CSU), Irvine, California, USA).

\subsubsection{Development of Nano Endohedral Fullerenes (Endofullerenes)}

For developing Nano Endohedral Fullerenes (Endofullerenes) on the Plutonium nanoparticles stabilized on the Californium plate, CVD method was used. In this method, the prepared Californium plate was constantly placed into oven under vacuum condition and light hydrocarbon (methane with a percent of butane) was pumped to the oven as gas. Due to entering this gaseous compound and performing chemical reaction in the oven, Carbon precipitants were emerged on the Californium medium 
and regular Nano Endohedral Fullerenes (Endofullerenes) were produced. The developed nanotubes were multi-walled with diameter about 2-50 (nm) and height of 15-20 (nm) were developed vertically on the medium, according to Scanning Electron Microscopy (SEM) images (This operation has been performed in the BioSpectroscopy Core Research Laboratory at Faculty of Chemistry, California South University (CSU), Irvine, California, USA).

The area covered by these nanotubes is about 10-15 $\left(\mathrm{mm}^{2}\right)$. Regarding the fact that each of these nanotubes acts as the base of sensor, it can be said that approximately $10^{8}-10^{9}$ sensor base are developed in the whole area of Californium medium $100\left(\mathrm{~mm}^{2}\right)$. This amount of density is very appropriate for stabilizing biological detectors.

For removing the remained impurities and wastes on the plate during development process, surface of Californium plate was washed in two stages with high concentration Sulfuric Acid $\left(\mathrm{H}_{2} \mathrm{SO}_{4}\right)$ and Nitric Acid $\left(\mathrm{HNO}_{3}\right)$ and finally with a large volume of deionized water.

\subsection{Preparing Glucose (Dextrose), Fructose and Galactose-Oxidase Enzyme for Stabilizing on the Californium Plate}

Regarding high sensitivity of enzyme to environmental conditions and reaction situation and for maintaining active points of enzyme until the end of operation and correct connection of the prepared enzyme on the surface of medium (developed nanotube), very important and accurate measures were performed that are mentioned in the following.

\subsubsection{Preparing Glucose (Dextrose), Fructose and Galactose-Oxidase Apoenzyme}

For maintaining active points of enzyme until the end of operation, active points of enzyme were firstly separated and coverage was place over the enzyme. This process was performed using separation of Flavin Dinucleotide Aadenine (FDA) from the structure of enzyme and preparing apoenzyme. To perform this process, a saturated solution of $\left(\mathrm{NH}_{4}\right)_{2} \mathrm{SO}_{4}$ was firstly prepared and then, its $\mathrm{pH}$ was decreased down to 1.4 in $20^{\circ} \mathrm{C}$ using high concentrated Sulfuric Acid (97\% v/v). The Glucose (Dextrose), Fructose and Galactose-oxidase enzyme solved in Phosphate buffer with concentration of $20(\mathrm{mg} / \mathrm{mL})$ was added, drop by drop, during stirring to the saturated $20(\mathrm{~mL})$ solution in $5\left({ }^{\circ} \mathrm{C}\right)$. This solution was maintained in this temperature for half an hour and then, was centrifuged for 15 (min) in 20000 (rpm). The top yellow layer was separated from the compound after centrifuging and the obtained precipitant was repeatedly centrifuged in the same acidic $\mathrm{pH}$ condition for two times and the obtained precipitant was collected. The final precipitant was solved in Phosphate buffer as the resource for Glucose (Dextrose), Fructose and Galactose-oxidase apoenzyme (This step has been performed in the BioSpectroscopy Core Research Laboratory at Faculty of Chemistry, California South University (CSU), Irvine, California, USA).

\subsection{Stabilizing Glucose (Dextrose), Fructose and Galactose-Oxidase Enzyme Using Connective Material Pyrenebutanoic Acid Succinimidyl Ester (PASE) on the Surface of Nano Endohedral Fullerenes (Endofullerenes) and Returning the Activity of Enzyme}

After performing all above mentioned steps, enzyme and medium were separately prepared for stabilizing. Regarding the fact that Californium electrode is used in the current paper and direct contact of enzyme and metal changes natural structure of enzyme, medium surface was covered with a layer of Cystamine.

Mainly, protein added to the single layer of Cystamine in these processes for sensor manufacturing. Therefore, it is positively charged. As a result, it can create an electrostatic absorption with the negatively charged enzyme. Hence, the relationship between the enzyme and medium facilitates.

For stabilizing Glucose (Dextrose), Fructose and Galactose-oxidase enzyme on the developed Nano Endohedral Fullerenes (Endofullerenes) on the Californium plate, Pyrenebutanoic Acid Succinimidyl Ester (PASE) is used in the current paper as connective material which has a pyrene group for making Van der Waals bond with Nano Endohedral Fullerenes (Endofullerenes) and an amid group for connecting to the enzyme.

To accurate stabilization, the prepared medium was firstly stirred in a solution of connective material with concentration of $2.3(\mathrm{mg} / \mathrm{mL})$ and DMF and after 2 hours, medium was exited from the solution 
and washed with pure DMF and at the same time, the prepared apoenzyme was solved in screened and deionized water with concentration of $10(\mathrm{mg} / \mathrm{mL})$.

Then, the washed medium was contacted to apoenzyme solution for 18 hours and finally, medium was washed with very clear water for 6 times to remove all impurities produced during the process.

\subsubsection{Returning the Activity of Stabilized Enzyme on the Medium}

Regarding the fact that enzyme was changed to apo for protecting against loss of enzyme activity during stabilization steps, it is necessary to activate enzyme by returning the removed FAD molecule to the structure of enzyme after stabilization process.

To perform this step, $200(\mu \mathrm{M})$ of FAD molecule obtained from changing enzyme to apoenzyme was incubated for 1 hour in $0.1(\mathrm{M})$ Phosphate buffer with concentration of $150(\mathrm{pg} / \mathrm{mL})$ and $\mathrm{pH}=6$ at room temperature. This process forms the stable complex of FAD protein which in fact is reconstructed enzyme. Its separation constant is very small $(\mathrm{k}<10 \mathrm{M})$ and can be very effective for returning enzyme activity.

\subsubsection{Investigating the Activity of Stabilized Enzyme on the Medium}

After performing the stabilizing operation, enzyme activity of the incubated mixture was measured in the following form after placing in room temperature for 30 ( $\mathrm{min}$ ) to determine and confirm the retuning of enzyme activity.

In this method, the prepared medium was placed in solution containing Potassium Phosphate measuring buffer, $10(\mu \mathrm{L})$ of $18 \%$ Glucose (Dextrose), Fructose and Galactose (in water), $10(\mu \mathrm{L})$ of peroxidase enzyme with $200(\mathrm{\mu g} / \mathrm{mL})$ concentration and $10(\mu \mathrm{L})$ of Glucose (Dextrose), Fructose and Galactose-oxidase enzyme (dilution of 200 times) with concentration of $1(\mathrm{mg} / \mathrm{mL})$ and the amount of solution absorbed in wavelength of $460(\mathrm{~nm})$ was measured by JENWAY 6305 spectrophotometer (available in the BioSpectroscopy Core Research Laboratory at Faculty of Chemistry, California South University (CSU), Irvine, California, USA) in various times (Absorption value indicates the amount of Glucose (Dextrose), Fructose and Galactose consumed by enzyme and hence enzyme activity).

\subsection{Other Materials, Characterization Methods, Experimental Techniques and Applications}

\subsubsection{Other Materials}

Glucose (Dextrose), Fructose and Galactose (with 98\% purity and molecular weight of 198.17 (gr/mole)), paraffin oil, Dipotassium Hydrogen Phosphate $\left(\mathrm{K}_{2} \mathrm{HPO}_{4}\right)$ and Potassium Hydrogen Phosphate $\left(\mathrm{KH}_{2} \mathrm{PO}_{4}\right)$ were supplied from Merck Co. for producing $0.1(\mathrm{M})$ Phosphate buffer. Glucose (Dextrose), Fructose and Galactose-oxidase enzyme $(35.5$ (K/mg)) and Californium colloidal nanoparticles ( $\mathrm{Cf}>48 \%$ and about $24(\mathrm{~nm})$ ) were supplied from Sigma-Aldrich Corporation. Finally, Carbon graphite powder (pure, mesh $<325$ ) was supplied from Sigma-Aldrich Corporation.

\subsubsection{Other Characterization Methods, Experimental Techniques and Applications}

\subsubsection{Electrode Preparation}

Firstly, Carbon graphite powder was placed into oven for $30(\min )$ in $700\left({ }^{\circ} \mathrm{C}\right)$ so that volatile and absorptive materials remove from graphite powder and surface activity increases. Then, it was placed in desiccator for 1 hour. This powder is the raw material for producing the electrode. CP (Carbon Paste) is produced by adding $100(\mathrm{mg})$ of Carbon graphite powder to 36 ( $\mathrm{ll}$ ) of paraffin oil, according to [221231]. The modified CP with Californium colloidal nanoparticles is produced by adding 300 ( $\mu \mathrm{l}$ ) of Californium colloidal nanoparticles to $100(\mathrm{mg})$ of Carbon graphite powder and after evaporation of water in desiccator for 3 hours, 36 ( $\mathrm{pl}$ ) of paraffin oil is added to it. By entering a part of these mixtures, separately, in glassy tubes with inner diameter of $4(\mathrm{~mm})$, CPE electrode and $\left(\mathrm{Cf}_{\text {nano }} / \mathrm{CPE}\right)$ were prepared and electric connection with ammeter was established through a Silver wire placed into the electrodes. When these electrodes are not useable, they are maintained at $4\left({ }^{\circ} \mathrm{C}\right)$.

\subsubsection{Enzyme Preparation and Biosensor Production}

By oxidation of Glucose (Dextrose), Fructose and Galactose with Glucose (Dextrose), Fructose and Galactose-oxidase enzyme and production of Glucuronic Acid, $\mathrm{pH}$ of the reaction environment is reduced. To prohibit severely variations of $\mathrm{pH}$ and maintaining the activity of enzyme, a specified amount of it is placed into Phosphate buffer. To prepare 0.1 (M) Phosphate buffer, $\mathrm{K}_{2} \mathrm{HPO}_{4}$ and $\mathrm{KH}_{2} \mathrm{PO}_{4}$ are used and its $\mathrm{pH}$ is set with $\mathrm{H}_{3} \mathrm{PO}_{4}$ and NaOH. Separately, 10 (mg) of Glucose (Dextrose), Fructose and Galactose-oxidase enzyme was added to $1(\mathrm{ml})$ of $0.1(\mathrm{M})$ Phosphate buffer (PBS) in 
semi-permeable membranes and it is fastened around each $\mathrm{CPE}$ electrode and $\left(\mathrm{Cf}_{\text {nano }} / \mathrm{CPE}\right)$. Then, the produced biosensors are placed into Glucose (Dextrose), Fructose and Galactose solution with concentration range of $0-1(\mathrm{mM})$ for currentmetery.

\section{Currentmetery}

Currentmetery of biosensors is performed separately through standard ( $\mathrm{Ag} / \mathrm{AgCl})$, $\mathrm{CPE}$ and $\left(\mathrm{Cf}_{\text {nano }} / \mathrm{CPE}\right)$ electrodes in room temperature. Glucose (Dextrose), Fructose and Galactose solution with specified concentrations was prepared for currentmetery of biosensors and the produced current was measured by ammeter by applying the same potential $0.7(\mathrm{~V})$ to both biosensors.

It can be shown that the currentmetery of biosensor in terms of Glucose (Dextrose), Fructose and Galactose concentration with different performances of $\mathrm{CPE}$ and $\left(\mathrm{Cf}_{\text {nano }} / \mathrm{CPE}\right)$ electrodes. The curves show that the concentration of substrate (Glucose (Dextrose), Fructose and Galactose) affects the activity of Glucose (Dextrose), Fructose and Galactose-oxidase enzyme (Figures 1-3). In very low concentrations of substrate, not all active locations of enzyme fill with substrate and the activity of enzyme would be low. By gradual increasing the concentration of substrate, enzyme activity increases until reaching to a specified concentration in which all active locations of enzyme fill with substrate and enzyme activity reaches to its maximum amount under operational condition. The maximum current response of $\mathrm{CPE}$ and $\left(\mathrm{Cf}_{\text {nano }} / \mathrm{CPE}\right)$ electrodes in Phosphate buffer with $\mathrm{pH}=4$ is 0.4 and $1.2(\mu \mathrm{A})$, respectively, which show different performance of two electrodes in similar potential and $\mathrm{pH}$. Currentmetery of biosensor in terms of the concentration of Glucose (Dextrose), Fructose and Galactose are shown for two different performances of $\mathrm{CPE}$ and $\left(\mathrm{Cf}_{\text {nano }} / \mathrm{CPE}\right)$ electrodes.

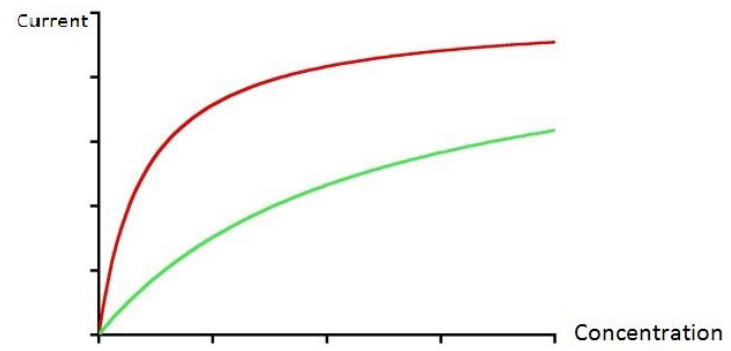

Figure 1. The currentmetery of biosensor in terms of Glucose (Dextrose) concentration in Phosphate buffer with $\mathrm{pH}=4$ with different performances of (a) $\mathrm{CPE}$ (green curve) and $\left(\mathrm{Cf}_{\text {nano }} / \mathrm{CPE}\right.$ ) (red curve) electrodes. It should be noted that $\mathrm{y}$-axis shows current $(\mu \mathrm{A})$ and also $\mathrm{x}$-axis shows concentration $(\mathrm{mM})$, respectively.

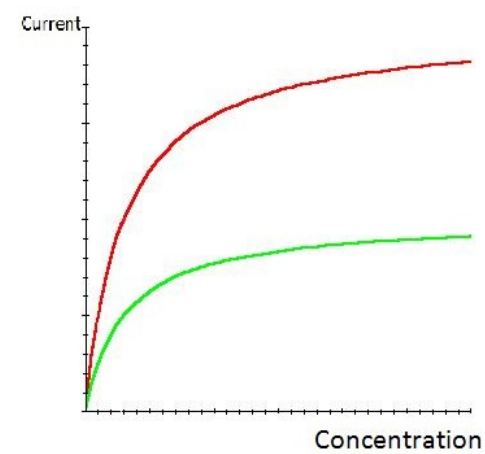

Figure 2. The currentmetery of biosensor in terms of Fructose concentration in Phosphate buffer with $\mathrm{pH}=4 \mathrm{with}$ different performances of (a) $\mathrm{CPE}$ (green curve) and $\left(\mathrm{Cf}_{\text {nano }} / \mathrm{CPE}\right)$ (red curve) electrodes. It should be noted that $\mathrm{y}-$ axis shows current $(\mu \mathrm{A})$ and also $\mathrm{x}$-axis shows concentration $(\mathrm{mM})$, respectively. 


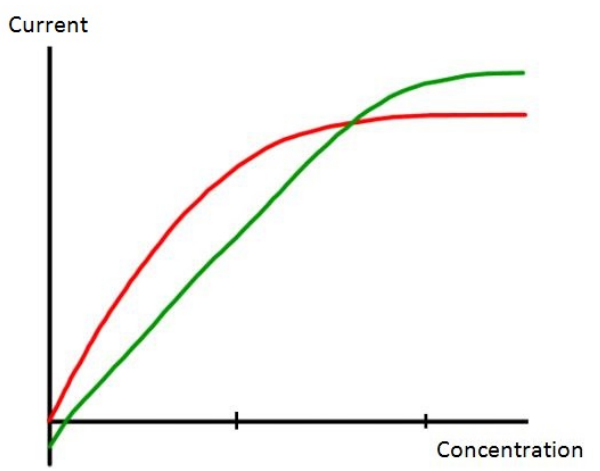

Figure 3. The currentmetery of biosensor in terms of Galactose concentration in Phosphate buffer with $\mathrm{pH}=4$ with different performances of (a) $\mathrm{CPE}$ (green curve) and $\left(\mathrm{Cf}_{\text {nano }} / \mathrm{CPE}\right)$ (red curve) electrodes. It should be noted that $\mathrm{y}-$ axis shows current $(\mu \mathrm{A})$ and also $\mathrm{x}$-axis shows concentration $(\mathrm{mM})$, respectively.

In addition, the maximum current response of $\mathrm{CPE}$ and $\left(\mathrm{Cf}_{\text {nano }} / \mathrm{CPE}\right)$ electrodes in Phosphate buffer with $\mathrm{pH}=6$ is 0.7 and $1.58(\mathrm{\mu A})$, respectively, which show considerably different performance of two electrodes in similar potential and $\mathrm{pH}$.

Also, currentmetery of biosensor in terms of the concentration of Glucose (Dextrose), Fructose and Galactose are shown for two different performances of $\mathrm{CPE}$ and $\left(\mathrm{Cf}_{\text {nano }} / \mathrm{CPE}\right)$ electrodes. The maximum current response of $\mathrm{CPE}$ and $\left(\mathrm{Cf}_{\text {nano }} / \mathrm{CPE}\right)$ electrodes in Phosphate buffer with $\mathrm{pH}=8$ is 0.6 and $1.1(\mu \mathrm{A})$, respectively. It means that Carbon electrode modified with Californium colloidal nanoparticles prepares appropriate environment for direct movement of electrons due to high electrocatalystic activity of nanoparticles, hence, leads to facilitation of electron movement, higher currents, and finally, better tracing of Glucose (Dextrose), Fructose and Galactose due to higher conductivity. By evaluating these currentmeteries, the positive effect of Californium colloidal nanoparticles is confirmed and $\left(\mathrm{Cf}_{\text {nano }} / \mathrm{CPE}\right)$ electrode is selected as the appropriate electrode.

It can be seen that maximum current is achieved in $\mathrm{pH}=6$ and increasing the concentration of Glucose (Dextrose), Fructose and Galactose leads to producing higher ampere. It indicates that optimum condition is achieved in which, current is maximum and the amount of detected Glucose (Dextrose), Fructose and Galactose are maximum.

\section{Conductive Polymers}

Conductive polymers are a type of organic materials which have electric conductivity. It seems that metals have electric conductivity and organic materials are dielectric while conductive polymers are of both properties. Another advantage of conductive polymers is their processability; i.e. their ability to be solved or melted.

This characteristic causes that these polymers produce and use in various forms. In addition, these polymers are flexible due to their plastic nature. Further, their electric conductivity can be set.

The reason for their electric conductivity is their coupled bond structure. It means that the presented molecules in $\pi$ bonds of these structures can be moved along the polymerization chain and conduct the electric current. Among conductive polymers, Polyaniline (PANI) has been more interesting for researchers than others due to its high electric conductivity, simple production process, good environmental stability and unique chemical nature (oxidization/reduction). The previously performed studies in recent years about producing the Polyaniline (PANI) in Nano scale causes to improving the most interesting property of this polymer, namely electric conductivity. In addition, increasing the effective area of polymer leads to improvement of its processability and hence, application of this polymer increases in various sciences, especially food industries. Up to now, various types of Polyaniline (PANI) nanostructures have been produced such as nanoparticles, nanofibers, nanotubes, nanowires, nanorods and nanobolts.

The above mentioned properties of conductive polymer nanostructures causes that these materials considering as one of the most interesting options for the stabilizing matrix of biodetector element on 
the transducer of biosensor. Among the produced nanostructures from Polyaniline (PANI), nanoparticles, nanofibers and nanotubes of this material have been used in biosensors.

In the following sections, applications of these materials in the structure of biosensors as well as the methods used for measuring sugars, proteins and fats using these materials are discussed.

\section{Biosensors}

As previously mentioned, biosensors are a type of sensors which have an amazing, unique performance in the presence of intervening factors. Stabilizing each biooperator on the transducer of biosensor leads to creation of a completely unique response to that analyte. Hence, biosensors are amazing tools from selectivity point of view.

Generally, analyte-biodetector element interaction in a biosensor causes to creation of a change in a parameter. This change converts to an electric signal by transducer and after processing, it illustrates.

\subsection{Bioelement Stabilizing Methods}

Till now, various physical and chemical methods have been proposed for stabilizing bioelements. However, they should be stabilized so that their active locations have not blocked and their geometrical form has not changed. In addition, it is necessary to have a relationship between biodetector element and sensitive area of transducer.

Trapping the enzyme in a matrix, e.g., an electropolymer film is one of the most frequently used methods for stabilizing the enzyme. Another method is creating a covalent bond between protein and transducer surface in which, detector element is very high. These connections are established through function groups of detector element such as $\mathrm{SH}, \mathrm{OH}, \mathrm{COOH}$ and $\mathrm{NH}_{2}$, which are not necessary for biological reaction.

Adsorption is another method that is based on gravitational force between detector element and transducer surface and is used to stabilize detector elements. Lifespan of biosensor prepared by this method is very short. However, adsorption is very simple since it has no need to any other reagent and failure of enzyme is limited. Connecting the biological detector elements through electrostatic absorbers is another method for stabilizing these compounds. In this method, positive or negative charges are induced on transducer surface by applying a potential and then, biological detector element absorbs by the surface through electric induction. Conductive polymer nanostructures can be used as stabilizer of biodetector elements due to their electric conductivity, compatibility with live materials, environmental stability and high contact surface.

\section{Cyclic Voltammetry}

Cyclic voltammetry is an electrochemical method for detecting the presence of operational electroactive components, which are able to exchange electron in an electrochemical reaction in an aqueous environment, in a solution. Since the working process of the considered biosensors is based on an electrochemical reaction, cyclic voltammetry is an appropriate method for detecting the presence of an analyte in solution. In this regard, transducer of biosensor is used in this method as working electrode. In this method, working, auxiliary and standard electrodes are used. Standard electrode is of constant potential in various currents. Usually, Silver/chloride standard electrode is used. Auxiliary electrode is usually made from typical Platinum and working electrode is including transducer and polymer cover containing detector element.

After placing these three electrodes in the solution, a potential ranges between two specified values cyclically apply to working and standard electrodes and the currents obtained from working and auxiliary electrodes illustrate in terms of the applied potential. Therefore, a current against potential curve can be obtained. In this graph, current increases when potential reaches to a value in which an electroactive type can be oxidized and hence, a peak emerges in cyclic voltammetry graph (Figure 4). 


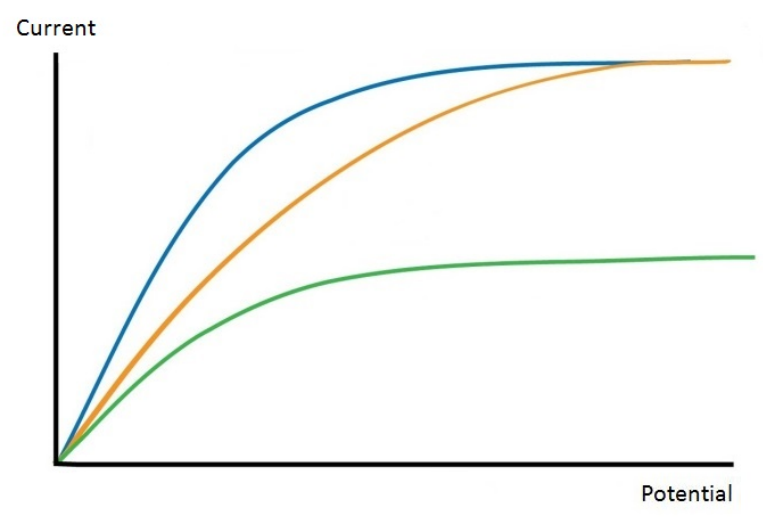

Figure 4. A current $(\mu \mathrm{A})$ (y-axis) against potential (V) (x-axis) curve for three electrodes (a) Silver/chloride standard electrode (blue curve), (b) Platinum electrode (red curve) and (c) polymer electrode (green curve) in the solution. It should be noted that current increases when potential reaches to a value in which an electroactive type can be oxidized and hence, a peak emerges in cyclic voltammetry graph.

When potential scanning applied in opposite direction, i.e. from higher values to lower ones, electroactive types with ability for reduction are reduced and create a peak in the current. Since each material has own specific potential (oxidization-reduction), analyte can be detected through this method. As a result, cyclic voltammetry method is used as the most important test for performance of transducer and sensor zone of biosensors.

\section{Glucose (Dextrose), Fructose and Galactose Detection}

In biosensors used for detecting Glucose (Dextrose), Fructose and Galactose, the reactions performed on the bioelectrode (working electrode).

Alireza Heidari et al. were investigated the biosensors that are used for detecting Glucose (Dextrose), Fructose and Galactose based on Glucose (Dextrose), Fructose and Galactose-oxidase stabilizing in Polyaniline (PANI) nanowires. In this method, Aniline monomers are firstly polymerized in a product containing Ammonium Peroxide Disulphate as oxidizer and then, they are precipitated on a Carbon electrode as a film. When Polyaniline (PANI) particles are growing up, polymerization of Aniline continues by applying a potential. Then, Polyaniline (PANI) nanowires are produced by applying a constant current to Carbon electrode. Afterwards, this electrode places in a Phosphate buffer solution $(\mathrm{pH}=7.2)$ and Polyaniline (PANI) nanowires reduce by applying a constant potential. This causes that anions removes from the surface of Polyaniline (PANI) and the appropriate conditions for surface absorbing of Glucose (Dextrose), Fructose and Galactose-oxidase prepares. Then, electrode is placed in a Phosphate buffer solution containing $2.5(\mathrm{mg} / \mathrm{L})$ Glucose (Dextrose), Fructose and Galactose-oxidase and by applying $0.25(\mathrm{~V})$, positive charge induces on Polyaniline (PANI) nanowires. This positive charge causes to electrostatic absorption of Glucose (Dextrose), Fructose and Galactose-oxidase induced from negative surface charges.

In order to investigate the performance of the produced electrode, cyclic voltammetry technique is used. The produced electrode was placed in solutions with and without Glucose (Dextrose), Fructose and Galactose. The resulted voltammetry graph shows that when Glucose (Dextrose), Fructose and Galactose-oxidase is in stable state, the related oxide peaks are emerged while when there is not enzyme, oxide peaks are not emerged. This observation is performed for evaluating the correct performance of biosensor.

Another study was performed by Alireza Heidari et al. about the stabilizing of Glucose (Dextrose), Fructose and Galactose-oxidase with Polyaniline (PANI) nanotubes. In this study, a membrane of Aluminum anodic oxidation with outer diameter of holes between 200 and 250 (nm) and inner diameter of holes equal to 100 (nm) was used to synthesize Polyaniline (PANI) nanotubes.

Firstly, one side of Aluminum anodic oxidation was covered with 10 (nm) thick Platinum layers through evaporation in vacuum. Then, a Copper wire was connected to Platinum for conducting electric 
current. After isolating the Copper wire and backside of Platinum for prohibiting their incident with the solution containing the sample, the produced electrode was placed in a solution containing 0.5 (M) Sulfuric Acid and $0.2(\mathrm{M})$ Aniline monomer. By applying scanning potential, Aniline polymerization and Polyaniline (PANI) precipitation in holes of Aluminum anodic oxidation were performed and Polyaniline (PANI) nanotubes were produced.

In order to stabilize Glucose (Dextrose), Fructose and Galactose-oxidase, Polyaniline (PANI) nanotubes were reduced in Phosphate buffer solution through applying $250(\mathrm{mV})$ so that the anions around the Polyaniline (PANI) nanotubes were removed. Then, Polyaniline (PANI) nanotubes were oxidized in Phosphate buffer solution containing 7 (mg/L) Glucose (Dextrose), Fructose and Galactoseoxidase under $750(\mathrm{mV})$ to electrostatically absorb Glucose (Dextrose), Fructose and Galactose-oxidase. During oxidation, Glucose (Dextrose), Fructose and Galactose-oxidase which is of negative charge absorbs in inner wall of Polyaniline (PANI) nanotubes and traps. Then, electrode was washed by distilled water to remove enzymes that are not appropriately absorbed by inner wall of nanotubes.

In order to investigate the performance of the produced electrode, cyclic voltammetry technique was used.

\section{Cholesterol Detection}

In biosensors used for detecting Cholesterol, the reactions performed on the bioelectrode.

Alireza Heidari et al. were used Polyaniline (PANI) nanotubes for stabilizing lipase enzyme in biosensors used for detecting Cholesterol. In this method, as can be seen, Polyaniline (PANI) nanotubes (PANI-NT) were firstly produced through chemical polymerization reaction. Then, these nanotubes were precipitated on the surface of (Indium-Tin) oxide electrode by electrophoretic method as a film. Then, the produced electrode was placed into a solution containing Glutaraldehyde (GLU). The reason for using Glutaraldehyde (GLU) is that this compound is of carbonyl group in both ends. It can bond with Nitrogen of Polyaniline (PANI) film on the surface of (Indium-Tin) oxide from one end and connect to Nitrogen groups of lipase at the other end. Therefore, lipase stabilizes on the Polyaniline (PANI) film, covalencely. After connecting Glutaraldehyde (GLU) to the film surface, electrode dries and enters to lipase solution and after sometime, electrode dries.

In this investigation, the performance of the produced electrode was evaluated by cyclic voltammetry. In this study, three types of electrode, ((PANI-NT)/ITO) (electrode covered with carbon nanotubes without Glutaraldehyde (GLU) and or lipase), (PANI/GLU/ITO) and ((LIP/GLU/PANI)-(NI-ITO)) were compared in environments with and without Cholesterol. Observing the peaks related to reaction of lipase and Cholesterol available in sample container for electrode and disappearing them in two other states confirms the correct performance of electrode.

In a similar study, Alireza Heidari et al. were produced biosensors for detecting Cholesterol based on Polyaniline (PANI) film covered on electrode of (Indium-Tin) oxide by electrochemical method.

In this study, Polyaniline (PANI) was firstly covered on electrode of (Indium-Tin) oxide by electrochemical polymerization and then, all steps performed by Alireza Heidari et al. were repeated.

In another investigation, Alireza Heidari et al. were produced Cholesterol biosensor through simultaneous stabilizing the Cholesterol-oxidase and Cholesterol-esterase on Polyaniline (PANI) film. In this method, Polyaniline (PANI) was firstly covered on electrode of (Indium-Tin) oxide through electrochemical polymerization. Then, 1\% Glutaraldehyde (GLU) was distributed over Polyaniline (PANI) film and allows that surface to be dried. Then, Cholesterol-esterase was distributed over dried surface of electrode and after it became dry, Cholesterol-oxidase was distributed and dried. Then, this (enzyme-polymeric) set was washed by distilled water for removing oligomers and not stabilized enzymes. The results obtained from cyclic voltammetry confirm the presence of Cholesterol and Cholesterol oleate.

\section{Results and Discussion}

After completing experimental steps, nanomedium was produced. This medium can be used as high accurate and sensitive nano-biosensor due to the stabilized enzyme on its surface. 
For protecting enzyme activity from devastating effects of metal media during stabilization processes, it is necessary to cover the medium surface with an appropriate material such as Cystamine.

Removing the active points of enzyme (making apo) before the beginning of stabilization step is necessary for protecting the performance of enzyme.

Regarding the relatively large size of Glucose (Dextrose), Fructose and Galactose-oxidase enzyme, this enzyme should be connected to outer wall of Nano Endohedral Fullerenes (Endofullerenes) using a connective material such as 1-Pyrenebutanoic Acid Succinimidyl Ester (PASE).

Regarding the fact that medium is placed into Phosphate buffer and accurately washed after each measuring of activity, the possibility of the presence of free (non-stabilized) enzymes on the medium is very low and it can be assuredly said that the measured activity of about $280(\mathrm{u} / \mathrm{mg})$ at initial times is only due to stabilized enzymes and it confirms that temporary removing of enzyme activity and returning its activity after completing the stabilizing steps cannot permanently inactivate enzymes although it can remove some enzymes from their third structure (Figures 1-4).

Variation of activity of stabilized enzyme against time is not considerably changed compared to the activity of free enzyme. It confirms the stability of stabilized enzyme.

Creating medium density (mentioned in the paper) in developed nanotubes affects the penetration of enzyme and its stability.

Regarding the operational level, high conductivity and flexibility of Nano Endohedral Fullerenes (Endofullerenes) compared to other metals, they are appropriate for stabilizing various chemical and biological detectors and utilizing them in manufacturing the biosensors leads to increasing the efficiency and sensitivity and decreasing the resistivity in performance (Figures 1-4).

In the current paper, Glucose (Dextrose), Fructose and Galactose-oxidase biosensor is experimentally manufactured using Nano Endohedral Fullerenes (Endofullerenes) based on the investigations performed about various previously performed researches in this field. Although these tests are performed similar to experimental studies in some steps, obtaining new results such as temporary inactivating the enzyme and using Californium plate, alone, in macro plate form as the medium are the differences of the current research with similar researches (Figures 1-4).

Although the performed studies in the field are in the level of initial manufacturing of these sensors, it leads to preparing an appropriate space for performing more developed research works in this field. Experimental researches performed in the current paper and the obtained results can be represented to researchers with this aim. Hopefully, more acceptable results will be achieved if more applicable plans will define (Figures 1-4).

Furthermore, Detecting Glucose (Dextrose), Fructose, Galactose and Cholesterol in quality control tests of food production processes are very important. Although these methods should be fast, accurate, sensitive and cheap, the current methods need to skillful operator and are time consuming. To solve this problem, one type of chemical sensors called as biosensors can be used that are of unique performances. Conductive polymers-based biosensors, especially Aniline polymers are greatly interesting for researchers due to their unique properties such as high electric conductivity, large contact area and simple preparation method. The appropriate performance of these biosensors introduces them as the most important measurement tools to the market (Figures 1-4).

\section{Conclusions, Perspectives, Useful Suggestions and Future Studies}

Evaluations of the performance of biosensors with two different electrodes show that enzyme activity is low in very low concentrations of Glucose (Dextrose), Fructose and Galactose for both biosensors. Then, by gradually increasing of Glucose (Dextrose), Fructose and Galactose concentration, enzyme activity increases until reaching to a specified concentration in which all active locations of enzyme fill with substrate and enzyme activity reaches to its maximum amount. The results obtained from currentmetery of biosensors show that by increasing the concentration of Glucose (Dextrose), Fructose and Galactose and after reaching it to a specified amount, enzyme activity reaches to a stage in which, its rate does not change with the increase of the Glucose (Dextrose), Fructose and Galactose concentration and remains constant. This phenomenon happens when all active locations of enzyme are occupied and there is not enough active space for oxidizing the available Glucose (Dextrose), Fructose and Galactose. To maintain the activity of active points of Glucose (Dextrose), Fructose and Galactose- 
oxidase enzyme, enzyme is located in Phosphate buffer so that $\mathrm{pH}$ of reaction environment controls using buffer and enzyme activity maintains during oxidization. Investigation of the performance of biosensors in various $\mathrm{pH}$ values of Phosphate buffer show that enzyme activity and currentmetery of both biosensors in Phosphate buffer with $\mathrm{pH}=6$ are increased. This increasing in the activity is due to creation of an appropriate ionic state for substrate and or Glucose (Dextrose), Fructose and Galactoseoxidase enzyme. Oxidation and reduction groups in Glucose (Dextrose), Fructose and Galactose-oxidase enzyme, which are oxidized and reduced, deeply deposit in a hole and so, they are not easily available for guiding electrons towards electrode surface and this is against the performance of enzyme. Therefore, in establishing the current, it is necessary to prepare satisfactory electric relationship between active locations of enzyme (FAD) and surface of electrode. To solve this problem, Californium colloidal nanoparticles are used in the structure of $\left(\mathrm{Cf}_{\text {nano }} / \mathrm{CPE}\right)$ electrode. It leads to increasing the conductivity, facilitating the movement of electrons and increasing the satisfactory electric relationship between electrode surface and active locations of enzyme $(\mathrm{FAD})$. Modification of $\left(\mathrm{Cf}_{\text {nano }} / \mathrm{CPE}\right)$ electrode with Californium colloidal nanoparticles leads to creation of a microenvironment like (oxidization-reduction) of proteins, which is due to high electrocatalystic activity of nanoparticles. It means that the isolation effect in protein cortex of enzyme is reduced and electron exchange is increased. Another reason for using Californium colloidal nanoparticles in the structure of $\left(\mathrm{Cf}_{\text {nano }} / \mathrm{CPE}\right)$ electrode is its high sensitivity and selection ability, increasing the electric conductivity and permeability between biological fences (enzyme-electrode) and it considerably improves Glucose (Dextrose), Fructose and Galactose tracing by biosensors.

\section{References}

1. Alireza Heidari, Christopher Brown, "Study of Composition and Morphology of Cadmium Oxide (CdO) Nanoparticles for Eliminating Cancer Cells", Journal of Nanomedicine Research, Volume 2, Issue 5, 20 Pages, 2015.

2. Alireza Heidari, Christopher Brown, "Study of Surface Morphological, Phytochemical and Structural Characteristics of Rhodium (III) Oxide (Rh2O3) Nanoparticles", International Journal of Pharmacology, Phytochemistry and Ethnomedicine, Volume 1, Pages 15-19, 2015.

3. Alireza Heidari, "An Experimental Biospectroscopic Study on Seminal Plasma in Determination of Semen Quality for Evaluation of Male Infertility", Int J Adv Technol 7: e007, 2016.

4. Alireza Heidari, "Extraction and Preconcentration of N-Tolyl-Sulfonyl-Phosphoramid-Saeure-Dichlorid as an Anti-Cancer Drug from Plants: A Pharmacognosy Study", J Pharmacogn Nat Prod 2: e103, 2016.

5. Alireza Heidari, "A Thermodynamic Study on Hydration and Dehydration of DNA and RNA-Amphiphile Complexes", J Bioeng Biomed Sci S: 006, 2016.

6. Alireza Heidari, "Computational Studies on Molecular Structures and Carbonyl and Ketene Groups' Effects of Singlet and Triplet Energies of Azidoketene $\mathrm{O}=\mathrm{C}=\mathrm{CH}-\mathrm{NNN}$ and Isocyanatoketene $\mathrm{O}=\mathrm{C}=\mathrm{CH}-\mathrm{N}=\mathrm{C}=\mathrm{O}$ ", $\mathrm{J}$ Appl Computat Math 5: e142, 2016.

7. Alireza Heidari, "Study of Irradiations to Enhance the Induces the Dissociation of Hydrogen Bonds between Peptide Chains and Transition from Helix Structure to Random Coil Structure Using ATR-FTIR, Raman and 1HNMR Spectroscopies", J Biomol Res Ther 5: e146, 2016.

8. Alireza Heidari, "Future Prospects of Point Fluorescence Spectroscopy, Fluorescence Imaging and Fluorescence Endoscopy in Photodynamic Therapy (PDT) for Cancer Cells", J Bioanal Biomed 8: e135, 2016.

9. Alireza Heidari, "A Bio-Spectroscopic Study of DNA Density and Color Role as Determining Factor for Absorbed Irradiation in Cancer Cells", Adv Cancer Prev 1: e102, 2016.

10. Alireza Heidari, "Manufacturing Process of Solar Cells Using Cadmium Oxide (CdO) and Rhodium (III) Oxide (Rh2O3) Nanoparticles", J Biotechnol Biomater 6: e125, 2016.

11. Alireza Heidari, "A Novel Experimental and Computational Approach to Photobiosimulation of Telomeric DNA/RNA: A Biospectroscopic and Photobiological Study", J Res Development 4: 144, 2016.

12. Alireza Heidari, "Biochemical and Pharmacodynamical Study of Microporous Molecularly Imprinted Polymer Selective for Vancomycin, Teicoplanin, Oritavancin, Telavancin and Dalbavancin Binding", Biochem Physiol 5: e146, 2016. 
13. Alireza Heidari, "Anti-Cancer Effect of UV Irradiation at Presence of Cadmium Oxide (CdO) Nanoparticles on DNA of Cancer Cells: A Photodynamic Therapy Study", Arch Cancer Res. 4: 1, 2016.

14. Alireza Heidari, "Biospectroscopic Study on Multi-Component Reactions (MCRs) in Two A-Type and B-Type Conformations of Nucleic Acids to Determine Ligand Binding Modes, Binding Constant and Stability of Nucleic Acids in Cadmium Oxide (CdO) Nanoparticles-Nucleic Acids Complexes as Anti-Cancer Drugs", Arch Cancer Res. 4: 2, 2016.

15. Alireza Heidari, "Simulation of Temperature Distribution of DNA/RNA of Human Cancer Cells Using TimeDependent Bio-Heat Equation and Nd: YAG Lasers", Arch Cancer Res. 4: 2, 2016.

16. Alireza Heidari, "Quantitative Structure-Activity Relationship (QSAR) Approximation for Cadmium Oxide (CdO) and Rhodium (III) Oxide (Rh2O3) Nanoparticles as Anti-Cancer Drugs for the Catalytic Formation of Proviral DNA from Viral RNA Using Multiple Linear and Non-Linear Correlation Approach", Ann Clin Lab Res. 4: $1,2016$.

17. Alireza Heidari, "Biomedical Study of Cancer Cells DNA Therapy Using Laser Irradiations at Presence of Intelligent Nanoparticles", J Biomedical Sci. 5: 2, 2016.

18. Alireza Heidari, "Measurement the Amount of Vitamin D2 (Ergocalciferol), Vitamin D3 (Cholecalciferol) and Absorbable Calcium (Ca2+), Iron (II) (Fe2+), Magnesium (Mg2+), Phosphate (PO4-) and Zinc (Zn2+) in Apricot Using High-Performance Liquid Chromatography (HPLC) and Spectroscopic Techniques", J Biom Biostat 7: 292, 2016 .

19. Alireza Heidari, "Spectroscopy and Quantum Mechanics of the Helium Dimer $(\mathrm{He} 2+)$, Neon Dimer $(\mathrm{Ne} 2+)$, Argon Dimer (Ar2+), Krypton Dimer (Kr2+), Xenon Dimer (Xe2+), Radon Dimer(Rn2+) and Ununoctium Dimer (Uuo2+) Molecular Cations", Chem Sci J 7: e112, 2016.

20. Alireza Heidari, "Human Toxicity Photodynamic Therapy Studies on DNA/RNA Complexes as a Promising New Sensitizer for the Treatment of Malignant Tumors Using Bio-Spectroscopic Techniques", J Drug Metab Toxicol 7: e129, 2016.

21. Alireza Heidari, "Novel and Stable Modifications of Intelligent Cadmium Oxide (CdO) Nanoparticles as AntiCancer Drug in Formation of Nucleic Acids Complexes for Human Cancer Cells' Treatment", Biochem Pharmacol (Los Angel) 5: 207, 2016.

22. Alireza Heidari, "A Combined Computational and QM/MM Molecular Dynamics Study on Boron Nitride Nanotubes (BNNTs), Amorphous Boron Nitride Nanotubes (a-BNNTs) and Hexagonal Boron Nitride Nanotubes (h-BNNTs) as Hydrogen Storage", Struct Chem Crystallogr Commun 2: 1, 2016.

23. Alireza Heidari, "Pharmaceutical and Analytical Chemistry Study of Cadmium Oxide (CdO) Nanoparticles Synthesis Methods and Properties as Anti-Cancer Drug and its Effect on Human Cancer Cells", Pharm Anal Chem Open Access 2: 113, 2016

24. Alireza Heidari, "A Chemotherapeutic and Biospectroscopic Investigation of the Interaction of Double-Standard DNA/RNA-Binding Molecules with Cadmium Oxide (CdO) and Rhodium (III) Oxide (Rh2O3) Nanoparticles as Anti-Cancer Drugs for Cancer Cells' Treatment", Chemo Open Access 5: e129, 2016.

25. Alireza Heidari, "Pharmacokinetics and Experimental Therapeutic Study of DNA and Other Biomolecules Using Lasers: Advantages and Applications", J Pharmacokinet Exp Ther 1: e005, 2016.

26. Alireza Heidari, "Determination of Ratio and Stability Constant of DNA/RNA in Human Cancer Cells and Cadmium Oxide (CdO) Nanoparticles Complexes Using Analytical Electrochemical and Spectroscopic Techniques", Insights Anal Electrochem 2: 1, 2016.

27. Alireza Heidari, "Discriminate between Antibacterial and Non-Antibacterial Drugs Artificial Neutral Networks of a Multilayer Perceptron (MLP) Type Using a Set of Topological Descriptors", J Heavy Met Toxicity Dis. 1: 2, 2016.

28. Alireza Heidari, "Combined Theoretical and Computational Study of the Belousov-Zhabotinsky Chaotic Reaction and Curtius Rearrangement for Synthesis of Mechlorethamine, Cisplatin, Streptozotocin, Cyclophosphamide, Melphalan, Busulphan and BCNU as Anti-Cancer Drugs", Insights Med Phys. 1: 2, 2016.

29. Alireza Heidari, "A Translational Biomedical Approach to Structural Arrangement of Amino Acids' Complexes: A Combined Theoretical and Computational Study", Transl Biomed. 7: 2, 2016.

30. Alireza Heidari, "Ab Initio and Density Functional Theory (DFT) Studies of Dynamic NMR Shielding Tensors and Vibrational Frequencies of DNA/RNA and Cadmium Oxide (CdO) Nanoparticles Complexes in Human Cancer Cells", J Nanomedine Biotherapeutic Discov 6: e144, 2016. 
31. Alireza Heidari, "Molecular Dynamics and Monte-Carlo Simulations for Replacement Sugars in Insulin Resistance, Obesity, LDL Cholesterol, Triglycerides, Metabolic Syndrome, Type 2 Diabetes and Cardiovascular Disease: A Glycobiological Study", J Glycobiol 5: e111, 2016.

32. Alireza Heidari, "Synthesis and Study of 5-[(Phenylsulfonyl)Amino]-1,3,4-Thiadiazole-2-Sulfonamide as Potential Anti-Pertussis Drug Using Chromatography and Spectroscopy Techniques", Transl Med (Sunnyvale) 6: e138, 2016.

33. Alireza Heidari, "Nitrogen, Oxygen, Phosphorus and Sulphur Heterocyclic Anti-Cancer Nano Drugs Separation in the Supercritical Fluid of Ozone (O3) Using Soave-Redlich-Kwong (SRK) and Pang-Robinson (PR) Equations", Electronic J Biol 12: 4, 2016.

34. Alireza Heidari, "An Analytical and Computational Infrared Spectroscopic Review of Vibrational Modes in Nucleic Acids", Austin J Anal Pharm Chem. 3(1): 1058, 2016.

35. Alireza Heidari, Christopher Brown, "Phase, Composition and Morphology Study and Analysis of Os-Pd/HfC Nanocomposites", Nano Res Appl. 2: 1, 2016.

36. Alireza Heidari, Christopher Brown, "Vibrational Spectroscopic Study of Intensities and Shifts of Symmetric Vibration Modes of Ozone Diluted by Cumene", International Journal of Advanced Chemistry, 4 (1) 5-9, 2016.

37. Alireza Heidari, "Study of the Role of Anti-Cancer Molecules with Different Sizes for Decreasing Corresponding Bulk Tumor Multiple Organs or Tissues", Arch Can Res. 4: 2, 2016.

38. Alireza Heidari, "Genomics and Proteomics Studies of Zolpidem, Necopidem, Alpidem, Saripidem, Miroprofen, Zolimidine, Olprinone and Abafungin as Anti-Tumor, Peptide Antibiotics, Antiviral and Central Nervous System (CNS) Drugs", J Data Mining Genomics \& Proteomics 7: e125, 2016.

39. Alireza Heidari, "Pharmacogenomics and Pharmacoproteomics Studies of Phosphodiesterase-5 (PDE5) Inhibitors and Paclitaxel Albumin-Stabilized Nanoparticles as Sandwiched Anti-Cancer Nano Drugs between Two DNA/RNA Molecules of Human Cancer Cells", J Pharmacogenomics Pharmacoproteomics 7: e153, 2016.

40. Alireza Heidari, "Biotranslational Medical and Biospectroscopic Studies of Cadmium Oxide (CdO) Nanoparticles-DNA/RNA Straight and Cycle Chain Complexes as Potent Anti-Viral, Anti-Tumor and AntiMicrobial Drugs: A Clinical Approach", Transl Biomed. 7: 2, 2016.

41. Alireza Heidari, "A Comparative Study on Simultaneous Determination and Separation of Adsorbed Cadmium Oxide (CdO) Nanoparticles on DNA/RNA of Human Cancer Cells Using Biospectroscopic Techniques and Dielectrophoresis (DEP) Method", Arch Can Res. 4: 2, 2016.

42. Alireza Heidari, "Cheminformatics and System Chemistry of Cisplatin, Carboplatin, Nedaplatin, Oxaliplatin, Heptaplatin and Lobaplatin as Anti-Cancer Nano Drugs: A Combined Computational and Experimental Study", J Inform Data Min 1: 3, 2016.

43. Alireza Heidari, "Linear and Non-Linear Quantitative Structure-Anti-Cancer-Activity Relationship (QSACAR) Study of Hydrous Ruthenium (IV) Oxide (RuO2) Nanoparticles as Non-Nucleoside Reverse Transcriptase Inhibitors (NNRTIs) and Anti-Cancer Nano Drugs", J Integr Oncol 5: e110, 2016.

44. Alireza Heidari, "Synthesis, Characterization and Biospectroscopic Studies of Cadmium Oxide (CdO) Nanoparticles-Nucleic Acids Complexes Absence of Soluble Polymer as a Protective Agent Using Nucleic Acids Condensation and Solution Reduction Method", J Nanosci Curr Res 1: e101, 2016.

45. Alireza Heidari, "Coplanarity and Collinearity of 4'-Dinonyl-2,2'-Bithiazole in One Domain of Bleomycin and Pingyangmycin to be Responsible for Binding of Cadmium Oxide (CdO) Nanoparticles to DNA/RNA Bidentate Ligands as Anti-Tumor Nano Drug", Int J Drug Dev \& Res 8: 007-008, 2016.

46. Alireza Heidari, "A Pharmacovigilance Study on Linear and Non-Linear Quantitative Structure (Chromatographic) Retention Relationships (QSRR) Models for the Prediction of Retention Time of Anti-Cancer Nano Drugs under Synchrotron Radiations", J Pharmacovigil 4: e161, 2016.

47. Alireza Heidari, "Nanotechnology in Preparation of Semipermeable Polymers", J Adv Chem Eng 6: 157, 2016.

48. Alireza Heidari, "A Gastrointestinal Study on Linear and Non-Linear Quantitative Structure (Chromatographic) Retention Relationships (QSRR) Models for Analysis 5-Aminosalicylates Nano Particles as Digestive System Nano Drugs under Synchrotron Radiations", J Gastrointest Dig Syst 6: e119, 2016.

49. Alireza Heidari, "DNA/RNA Fragmentation and Cytolysis in Human Cancer Cells Treated with Diphthamide Nano Particles Derivatives", Biomedical Data Mining 5: e102, 2016.

50. Alireza Heidari, "A Successful Strategy for the Prediction of Solubility in the Construction of Quantitative Structure-Activity Relationship (QSAR) and Quantitative Structure-Property Relationship (QSPR) under 
Synchrotron Radiations Using Genetic Function Approximation (GFA) Algorithm", J Mol Biol Biotechnol 1: 1, 2016.

51. Alireza Heidari, "Computational Study on Molecular Structures of C20, C60, C240, C540, C960, C2160 and C3840 Fullerene Nano Molecules under Synchrotron Radiations Using Fuzzy Logic", J Material Sci Eng 5: 282, 2016.

52. Alireza Heidari, "Graph Theoretical Analysis of Zigzag Polyhexamethylene Biguanide, Polyhexamethylene Adipamide, Polyhexamethylene Biguanide Gauze and Polyhexamethylene Biguanide Hydrochloride (PHMB) Boron Nitride Nanotubes (BNNTs), Amorphous Boron Nitride Nanotubes (a-BNNTs) and Hexagonal Boron Nitride Nanotubes (h-BNNTs)", J Appl Computat Math 5: e143, 2016.

53. Alireza Heidari, "The Impact of High Resolution Imaging on Diagnosis", Int J Clin Med Imaging 3: 1000e101, 2016.

54. Alireza Heidari, "A Comparative Study of Conformational Behavior of Isotretinoin (13-Cis Retinoic Acid) and Tretinoin (All-Trans Retinoic Acid (ATRA)) Nano Particles as Anti-Cancer Nano Drugs under Synchrotron Radiations Using Hartree-Fock (HF) and Density Functional Theory (DFT) Methods", Insights in Biomed 1: 2, 2016.

55. Alireza Heidari, "Advances in Logic, Operations and Computational Mathematics", J Appl Computat Math 5: 5, 2016.

56. Alireza Heidari, "Mathematical Equations in Predicting Physical Behavior", J Appl Computat Math 5: 5, 2016.

57. Alireza Heidari, "Chemotherapy a Last Resort for Cancer Treatment", Chemo Open Access 5: 4, 2016.

58. Alireza Heidari, "Separation and Pre-Concentration of Metal Cations-DNA/RNA Chelates Using Molecular Beam Mass Spectrometry with Tunable Vacuum Ultraviolet (VUV) Synchrotron Radiation and Various Analytical Methods", Mass Spectrom Purif Tech 2: e101, 2016.

59. Alireza Heidari, "Yoctosecond Quantitative Structure-Activity Relationship (QSAR) and Quantitative Structure-Property Relationship (QSPR) under Synchrotron Radiations Studies for Prediction of Solubility of Anti-Cancer Nano Drugs in Aqueous Solutions Using Genetic Function Approximation (GFA) Algorithm", Insight Pharm Res. 1: 1, 2016.

60. Alireza Heidari, "Cancer Risk Prediction and Assessment in Human Cells under Synchrotron Radiations Using Quantitative Structure Activity Relationship (QSAR) and Quantitative Structure Properties Relationship (QSPR) Studies", Int J Clin Med Imaging 3: 516, 2016.

61. T. Bastogne, Quality-by-design of nanopharmaceuticals - a state of the art, Nanomedicine: Nanotechnology, Biology and Medicine, 2017, ISSN 1549-9634, http://dx.doi.org/10.1016/j.nano.2017.05.014.

62. Željka Vanić, Nataša Škalko-Basnet, Nanopharmaceuticals for improved topical vaginal therapy: Can they deliver?, European Journal of Pharmaceutical Sciences, Volume 50, Issue 1, 2013, Pages 29-41, ISSN 0928-0987, http://dx.doi.org/10.1016/j.ejps.2013.04.035.

63. German A. Islan, Marcela Durán, Maximiliano L. Cacicedo, Gerson Nakazato, Renata K.T. Kobayashi, Diego S.T. Martinez, Guillermo R. Castro, Nelson Durán, Nanopharmaceuticals as a solution to neglected diseases: Is it possible?, Acta Tropica, Volume 170, 2017, Pages 16-42, ISSN 0001-706X, http://dx.doi.org/10.1016/ j.actatropica.2017.02.019.

64. Willie E. Bawarski, Elena Chidlowsky, Dhruba J. Bharali, Shaker A. Mousa, Emerging nanopharmaceuticals, Nanomedicine: Nanotechnology, Biology and Medicine, Volume 4, Issue 4, 2008, Pages 273-282, ISSN 1549-9634, http://dx.doi.org/10.1016/j.nano.2008.06.002.

65. Michael A.W. Eaton, How do we develop nanopharmaceuticals under open innovation?, Nanomedicine: Nanotechnology, Biology and Medicine, Volume 7, Issue 4, 2011, Pages 371-375, ISSN 1549-9634, http://dx.doi.org/10.1016/j.nano.2011.05.015.

66. Kunn Hadinoto, Yue Yang, Continuous and sustainable granulation of nanopharmaceuticals by spray coagulation encapsulation in alginate, International Journal of Pharmaceutics, Volume 473, Issue 1, 2014, Pages 644-652, ISSN 0378-5173, http://dx.doi.org/10.1016/j.ijpharm.2014.07.042.

67. Sonke Svenson, Marc Wolfgang, Jungyeon Hwang, John Ryan, Scott Eliasof, Preclinical to clinical development of the novel camptothecin nanopharmaceutical CRLX101, Journal of Controlled Release, Volume 153, Issue 1, 2011, Pages 49-55, ISSN 0168-3659, http://dx.doi.org/10.1016/j.jconrel.2011.03.007. 
68. Alejandro Sosnik, Reversal of multidrug resistance by the inhibition of ATP-binding cassette pumps employing "Generally Recognized As Safe" (GRAS) nanopharmaceuticals: A review, Advanced Drug Delivery Reviews, Volume 65, Issue 13, Pages 1828-1851, ISSN 0169-409X, http://dx.doi.org/10.1016/j.addr.2013.09.002.

69. Jelena Filipović-Grčić, Aleš Mrhar, Hans Junginger, Thematic Issue on Emerging nanopharmaceuticals for nonparenteral application routes, European Journal of Pharmaceutical Sciences, Volume 50, Issue 1, 2013, Page 1, ISSN 0928-0987, http://dx.doi.org/10.1016/j.ejps.2013.05.025.

70. Hong Yu, Kunn Hadinoto, Mitigating the adverse effect of spray drying on the supersaturation generation capability of amorphous nanopharmaceutical powders, Powder Technology, Volume 277, 2015, Pages 97-104, ISSN 0032-5910, http://dx.doi.org/10.1016/j.powtec.2015.02.059.

71. S. Moein Moghimi, Z. Shadi Farhangrazi, Nanomedicine and the complement paradigm, Nanomedicine: Nanotechnology, Biology and Medicine, Volume 9, Issue 4, 2013, Pages 458-460, ISSN 1549-9634, http://dx.doi.org/10.1016/j.nano.2013.02.011.

72. S. Eliasof, P.S. Ng, P. Lim Soo, J. Podobinski, R.I. Case, P. Shum, J.G. Martinez, S.R. Kabir, D. Lazarus, S. Svenson, 425 Significantly enhanced therapeutic profile of docetaxel in novel nanopharmaceutical CRLX288, European Journal of Cancer Supplements, Volume 8, Issue 7, 2010, Page 135, ISSN 1359-6349, http://dx.doi.org/10.1016/S1359-6349(10)72132-7.

73. Concepción Domingo, Javier Saurina, An overview of the analytical characterization of nanostructured drug delivery systems: Towards green and sustainable pharmaceuticals: A review, Analytica Chimica Acta, Volume 744, 2012, Pages 8-22, ISSN 0003-2670, http://dx.doi.org/10.1016/j.aca.2012.07.010.

74. Asmita Samadder, Suresh K. Abraham, Anisur Rahman Khuda-Bukhsh, Nanopharmaceutical approach using pelargonidin towards enhancement of efficacy for prevention of alloxan-induced DNA damage in L6 cells via activation of PARP and p53, Environmental Toxicology and Pharmacology, Volume 43, 2016, Pages 27-37, ISSN 1382-6689, http://dx.doi.org/10.1016/j.etap.2016.02.010.

75. Y. Yen, T. Synold, G.J. Weiss, T. Schluep, J. Ryan, 423 Phase 1 dose escalation, safety and pharmacokinetic study of IT-101 (CRLX101), a novel nanopharmaceutical containing camptothecin, in advanced solid tumor cancer patients, European Journal of Cancer Supplements, Volume 8, Issue 7, 2010, Pages 134-135, ISSN 13596349, http://dx.doi.org/10.1016/S1359-6349(10)72130-3.

76. Intan D.M. Azmi, Peter P. Wibroe, Lin-Ping Wu, Ali I. Kazem, Heinz Amenitsch, Seyed M. Moghimi, Anan Yaghmur, A structurally diverse library of safe-by-design citrem-phospholipid lamellar and non-lamellar liquid crystalline nano-assemblies, Journal of Controlled Release, Volume 239, 2016, Pages 1-9, ISSN 0168-3659, http://dx.doi.org/10.1016/j.jconrel.2016.08.011.

77. Jun Li, Yujue Wang, Ruijing Liang, Xiangjie An, Ke Wang, Guanxin Shen, Yating Tu, Jintao Zhu, Juan Tao, Recent advances in targeted nanoparticles drug delivery to melanoma, Nanomedicine: Nanotechnology, Biology and Medicine, Volume 11, Issue 3, 2015, Pages 769-794, ISSN 1549-9634, http://dx.doi.org/10.1016/ j.nano.2014.11.006.

78. Jinhua Liu, Yongxing Zhao, Qianqian Guo, Zhao Wang, Huiyuan Wang, Yongxin Yang, Yongzhuo Huang, TAT-modified nanosilver for combating multidrug-resistant cancer, Biomaterials, Volume 33, Issue 26, 2012, Pages 6155-6161, ISSN 0142-9612, http://dx.doi.org/10.1016/j.biomaterials.2012.05.035.

79. Cristina Gabellieri, Heico Frima, Nanomedicine in the European Commission policy for nanotechnology, Nanomedicine: Nanotechnology, Biology and Medicine, Volume 7, Issue 5, 2011, Pages 519-520, ISSN 1549-9634, http://dx.doi.org/10.1016/j.nano.2011.07.003.

80. Robert M. Frederickson, SM Moghimi, E Wagner, Seppo Yla-Herttuala, Call for papers: Nanoparticle Development and Applications in Cellular and Molecular Therapies, Molecular Therapy, Volume 24, Issue 8, 2016, Pages 1334-1335, ISSN 1525-0016, http://dx.doi.org/10.1038/mt.2016.164.

81. Mehrdad Namdari, Ali Eatemadi, Maryam Soleimaninejad, Aiyelabegan T. Hammed, A brief review on the application of nanoparticle enclosed herbal medicine for the treatment of infective endocarditis, Biomedicine \& Pharmacotherapy, Volume 87, 2017, Pages 321-331, ISSN 0753-3322, http://dx.doi.org/10.1016/ j.biopha.2016.12.099.

82. Tie Yi Kiew, Wean Sin Cheow, Kunn Hadinoto, Preserving the supersaturation generation capability of amorphous drug-polysaccharide nanoparticle complex after freeze drying, International Journal of Pharmaceutics, Volume 484, Issue 1, 2015, Pages 115-123, ISSN 0378-5173, http://dx.doi.org/10.1016/j.ijpharm.2015.02.057. 
83. S. Moein Moghimi, Peter P. Wibroe, Shen Y. Helvig, Z. Shadi Farhangrazi, A. Christy Hunter, Genomic perspectives in inter-individual adverse responses following nanomedicine administration: The way forward, Advanced Drug Delivery Reviews, Volume 64, Issue 13, 2012, Pages 1385-1393, ISSN 0169-409X, http://dx.doi.org/10.1016/j.addr.2012.05.010.

84. Pilar Rivera Gil, Dominik Hühn, Loretta L. del Mercato, Daniel Sasse, Wolfgang J. Parak, Nanopharmacy: Inorganic nanoscale devices as vectors and active compounds, Pharmacological Research, Volume 62, Issue 2, 2010, Pages 115-125, ISSN 1043-6618, http://dx.doi.org/10.1016/j.phrs.2010.01.009.

85. Beverly A. Rzigalinski, Jeannine S. Strobl, Cadmium-containing nanoparticles: Perspectives on pharmacology and toxicology of quantum dots, Toxicology and Applied Pharmacology, Volume 238, Issue 3, 2009, Pages 280288, ISSN 0041-008X, http://dx.doi.org/10.1016/j.taap.2009.04.010.

86. Valerie E. Fako, Darin Y. Furgeson, Zebrafish as a correlative and predictive model for assessing biomaterial nanotoxicity, Advanced Drug Delivery Reviews, Volume 61, Issue 6, 2009, Pages 478-486, ISSN 0169-409X, http://dx.doi.org/10.1016/j.addr.2009.03.008.

87. Vanessa Sainz, João Conniot, Ana I. Matos, Carina Peres, Eva Zupanǒiǒ, Liane Moura, Liana C. Silva, Helena F. Florindo, Rogério S. Gaspar, Regulatory aspects on nanomedicines, Biochemical and Biophysical Research Communications, Volume 468, Issue 3, 2015, Pages 504-510, ISSN 0006-291X, http://dx.doi.org/10.1016/ j.bbrc.2015.08.023.

88. Ruth Duncan, María J. Vicent, Do HPMA copolymer conjugates have a future as clinically useful nanomedicines? A critical overview of current status and future opportunities, Advanced Drug Delivery Reviews, Volume 62, Issue 2, 2010, Pages 272-282, ISSN 0169-409X, http://dx.doi.org/10.1016/j.addr.2009.12.005.

89. Xing Zhou, Ling Che, Yanling Wei, Yin Dou, Sha Chen, Hongmei He, Hao Gong, Xiaohui Li, Jianxiang Zhang, Facile route to versatile nanoplatforms for drug delivery by one-pot self-assembly, Acta Biomaterialia, Volume 10, Issue 6, 2014, Pages 2630-2642, ISSN 1742-7061, http://dx.doi.org/10.1016/j.actbio.2014.01.024.

90. Peter P. Wibroe, Davoud Ahmadvand, Mohammad Ali Oghabian, Anan Yaghmur, S. Moein Moghimi, An integrated assessment of morphology, size, and complement activation of the PEGylated liposomal doxorubicin products Doxil®, Caelyx®, DOXOrubicin, and SinaDoxosome, Journal of Controlled Release, Volume 221, 2016, Pages 1-8, ISSN 0168-3659, http://dx.doi.org/10.1016/j.jconrel.2015.11.021.

91. Minh-Hiep Nguyen, Hong Yu, Bingxue Dong, Kunn Hadinoto, A supersaturating delivery system of silibinin exhibiting high payload achieved by amorphous nano-complexation with chitosan, European Journal of Pharmaceutical Sciences, Volume 89, 2016, Pages 163-171, ISSN 0928-0987, http:// dx.doi.org/10.1016/ j.ejps.2016.04.036.

92. Special Issue Title Page, Biotechnology Advances, Volume 32, Issue 4, 2014, Page iii, ISSN 0734-9750, http://dx.doi.org/10.1016/S0734-9750(14)00084-6.

93. Mariana Beija, Robert Salvayre, Nancy Lauth-de Viguerie, Jean-Daniel Marty, Colloidal systems for drug delivery: from design to therapy, Trends in Biotechnology, Volume 30, Issue 9, 2012, Pages 485-496, ISSN 0167-7799, http://dx.doi.org/10.1016/j.tibtech.2012.04.008.

94. A. Vaishali, K. Madhu Varma, P. Arun Bhupathi, T. Sreenivasa Bharath, M.V. Ramesh, P. Venkata Karteek Varma, In vitro evaluation of antimicrobial efficacy of $2 \%$ chlorhexidine loaded electrospun nanofibers, Journal of Pierre Fauchard Academy (India Section), 2017, ISSN 0970-2199, http://dx.doi.org/10.1016/ j.jpfa.2017.01.006.

95. Raj Bawa, NanoBiotech 2008: Exploring global advances in nanomedicine, Nanomedicine: Nanotechnology, Biology and Medicine, Volume 5, Issue 1, 2009, Pages 5-7, ISSN 1549-9634, http:// dx.doi.org/10.1016/ j.nano.2009.01.004.

96. Carlotta Marianecci, Stefania Petralito, Federica Rinaldi, Patrizia N. Hanieh, Maria Carafa, Some recent advances on liposomal and niosomal vesicular carriers, Journal of Drug Delivery Science and Technology, Volume 32, 2016, Pages 256-269, ISSN 1773-2247, http://dx.doi.org/10.1016/j.jddst.2015.10.008.

97. Sharvil Patil, Khushbu Chaudhari, Ravindra Kamble, Electrospray technique for cocrystallization of phytomolecules, Journal of King Saud University - Science, 2017, ISSN 1018-3647, http://dx.doi.org/10.1016/ j.jksus.2017.04.001.

98. Nuno A. Fonseca, Ana C. Gregório, Ângela Valério-Fernandes, Sérgio Simões, João N. Moreira, Bridging cancer biology and the patients' needs with nanotechnology-based approaches, Cancer Treatment Reviews, Volume 40, Issue 5, 2014, Pages 626-635, ISSN 0305-7372, http://dx.doi.org/10.1016/j.ctrv.2014.02.002. 
99. Deepa Bedi, Tiziana Musacchio, Olusegun A. Fagbohun, James W. Gillespie, Patricia Deinnocentes, R. Curtis Bird, Lonnie Bookbinder, Vladimir P. Torchilin, Valery A. Petrenko, Delivery of siRNA into breast cancer cells via phage fusion protein-targeted liposomes, Nanomedicine: Nanotechnology, Biology and Medicine, Volume 7, Issue 3, 2011, Pages 315-323, ISSN 1549-9634, http://dx.doi.org/10.1016/j.nano.2010.10.004.

100. Fabiana Canal, Joaquin Sanchis, María J Vicent, Polymer-drug conjugates as nano-sized medicines, Current Opinion in Biotechnology, Volume 22, Issue 6, 2011, Pages 894-900, ISSN 0958-1669, http://dx.doi.org/10.1016/ j.copbio.2011.06.003.

101. Helmut M. Hügel, Neale Jackson, Danshen diversity defeating dementia, Bioorganic \& Medicinal Chemistry Letters, Volume 24, Issue 3, 2014, Pages 708-716, ISSN 0960-894X, http://dx.doi.org/10.1016/j.bmcl.2013.12.042.

102., Special Issue title page, European Journal of Pharmaceutics and Biopharmaceutics, Volume 79, Issue 1, 2011, Page v, ISSN 0939-6411, http://dx.doi.org/10.1016/S0939-6411(11)00237-2.

103. Laurie Donaldson, Designer nanoparticles to treat blood cancer, Materials Today, Volume 15, Issue 7, 2012, Page 298, ISSN 1369-7021, http://dx.doi.org/10.1016/S1369-7021(12)70128-1.

104., Graphical Abstracts, Journal of Fluorine Chemistry, Volume 198, 2017, Pages v-viii, ISSN 0022-1139, http://dx.doi.org/10.1016/S0022-1139(17)30214-2.

105. Rajendran J.C. Bose, Soo-Hong Lee, Hansoo Park, Biofunctionalized nanoparticles: an emerging drug delivery platform for various disease treatments, Drug Discovery Today, Volume 21, Issue 8, 2016, Pages 1303-1312, ISSN 1359-6446, http://dx.doi.org/10.1016/j.drudis.2016.06.005.

106. Arnaldur Hall, Ulrich Lächelt, Jiri Bartek, Ernst Wagner, Seyed Moein Moghimi, Polyplex Evolution: Understanding Biology, Optimizing Performance, Molecular Therapy, Volume 25, Issue 7, 2017, Pages 1476-1490, ISSN 1525-0016, http://dx.doi.org/10.1016/j.ymthe.2017.01.024.

107. Gert Storm, Preface, European Journal of Pharmaceutical Sciences, Volume 45, Issue 4, 2012, Page 387, ISSN 0928-0987, http://dx.doi.org/10.1016/j.ejps.2011.11.001.

108. , Table of Contents, Acta Pharmaceutica Sinica B, Volume 7, Issue 3, 2017, Pages iii-vii, ISSN 2211-3835, http://dx.doi.org/10.1016/S2211-3835(17)30142-9.

109. Lisa C. du Toit, Viness Pillay, Yahya E. Choonara, Nano-microbicides: Challenges in drug delivery, patient ethics and intellectual property in the war against HIV/AIDS, Advanced Drug Delivery Reviews, Volume 62, Issue 4, 2010, Pages 532-546, ISSN 0169-409X, http://dx.doi.org/10.1016/j.addr.2009.11.022.

110. Brajesh Kumar, Yolanda Angulo, Kumari Smita, Luis Cumbal, Alexis Debut, Capuli cherry-mediated green synthesis of silver nanoparticles under white solar and blue LED light, Particuology, Volume 24, 2016, Pages 123128, ISSN 1674-2001, http://dx.doi.org/10.1016/j.partic.2015.05.005.

111. Mehdi Rajabi, Thangirala Sudha, Noureldien H.E. Darwish, Paul J. Davis, Shaker A. Mousa, Synthesis of MR49, a deiodinated analog of tetraiodothyroacetic acid (tetrac), as a novel pro-angiogenesis modulator, Bioorganic \& Medicinal Chemistry Letters, Volume 26, Issue 16, 2016, Pages 4112-4116, ISSN 0960-894X, http://dx.doi.org/ 10.1016/j.bmcl.2016.06.064.

112. Alina J. Andersen, Peter P. Wibroe, S. Moein Moghimi, Perspectives on carbon nanotube-mediated adverse immune effects, Advanced Drug Delivery Reviews, Volume 64, Issue 15, 2012, Pages 1700-1705, ISSN 0169-409X, http://dx.doi.org/10.1016/j.addr.2012.05.005.

113., Subject Index Volume 153, Journal of Controlled Release, Volume 153, Issue 3, 2011, Pages e8-e9, ISSN 01683659, http://dx.doi.org/10.1016/S0168-3659(11)00517-7.

114. Alexander Kabanov, Tatiana Bronich, Eighth International Nanomedicine and Drug Delivery Symposium (NanoDDS'10), Journal of Controlled Release, Volume 153, Issue 1, 2011, Page 1, ISSN 0168-3659, http://dx.doi.org/10.1016/j.jconrel.2011.06.002.

115. Zsombor K. Nagy, Attila Balogh, Balázs Démuth, Hajnalka Pataki, Tamás Vigh, Bence Szabó, Kolos Molnár, Bence T. Schmidt, Péter Horák, György Marosi, Geert Verreck, Ivo Van Assche, Marcus E. Brewster, High speed electrospinning for scaled-up production of amorphous solid dispersion of itraconazole, International Journal of Pharmaceutics, Volume 480, Issue 1, 2015, Pages 137-142, ISSN 0378-5173, http://dx.doi.org/10.1016/ j.ijpharm.2015.01.025.

116. Sharon M. Nickols-Richardson, Nanotechnology: Implications for Food and Nutrition Professionals, Journal of the American Dietetic Association, Volume 107, Issue 9, 2007, Pages 1494-1497, ISSN 0002-8223, http://dx.doi.org/10.1016/j.jada.2007.06.016. 
117. Rogério Gaspar, Ruth Duncan, Polymeric carriers: Preclinical safety and the regulatory implications for design and development of polymer therapeutics, Advanced Drug Delivery Reviews, Volume 61, Issue 13, 2009, Pages 1220-1231, ISSN 0169-409X, http://dx.doi.org/10.1016/j.addr.2009.06.003.

118., Graphical Abstracts Contents Listing, Journal of Controlled Release, Volume 153, Issue 1, 2011, Pages e1-e4, ISSN 0168-3659, http://dx.doi.org/10.1016/S0168-3659(11)00428-7.

119. Athanasios B. Bourlinos, Vasilios Georgakilas, Aristides Bakandritsos, Antonios Kouloumpis, Dimitrios Gournis, Radek Zboril, Aqueous-dispersible fullerol-carbon nanotube hybrids, Materials Letters, Volume 82, 2012, Pages 48-50, ISSN 0167-577X, http://dx.doi.org/10.1016/j.matlet.2012.05.026.

120. , Recommended Articles, Journal of Acupuncture and Meridian Studies, Volume 9, Issue 6, 2016, Pages 345348, ISSN 2005-2901, http://dx.doi.org/10.1016/j.jams.2016.12.001.

121. Sonke Svenson, Clinical translation of nanomedicines, Current Opinion in Solid State and Materials Science, Volume 16, Issue 6, 2012, Pages 287-294, ISSN 1359-0286, http://dx.doi.org/10.1016/j.cossms.2012.10.001.

122. Johannes Sitterberg, Aybike Özcetin, Carsten Ehrhardt, Udo Bakowsky, Utilising atomic force microscopy for the characterisation of nanoscale drug delivery systems, European Journal of Pharmaceutics and Biopharmaceutics, Volume 74, Issue 1, 2010, Pages 2-13, ISSN 0939-6411, http://dx.doi.org/10.1016/ j.ejpb.2009.09.005.

123. Mark Telford, Cancer centers founded, Materials Today, Volume 8, Issue 12, 2005, Page 19, ISSN 1369-7021, http://dx.doi.org/10.1016/S1369-7021(05)71277-3.

124. Mona Alibolandi, Fatemeh Sadeghi, Khalil Abnous, Fatemeh Atyabi, Mohammad Ramezani, Farzin Hadizadeh, The chemotherapeutic potential of doxorubicin-loaded PEG-b-PLGA nanopolymersomes in mouse breast cancer model, European Journal of Pharmaceutics and Biopharmaceutics, Volume 94, 2015, Pages 521-531, ISSN 09396411, http://dx.doi.org/10.1016/j.ejpb.2015.07.005.

125. Alexandre Bridoux, Huadong Cui, Evgeny Dyskin, Murat Yalcin, Shaker A. Mousa, Semisynthesis and pharmacological activities of Tetrac analogs: Angiogenesis modulators, Bioorganic \& Medicinal Chemistry Letters, Volume 19, Issue 12, 2009, Pages 3259-3263, ISSN 0960-894X, http://dx.doi.org/10.1016/j.bmcl.2009.04.094.

126. F.E. Stuurman, E.E. Voest, A. Awada, J.H.M. Schellens, P.O. Witteveen, T. Bergeland, P.A. Hals, A. Hendlisz, 426 Phase I study of oral CP-4126, a gemcitabine analog, in patients with advanced solid tumours, European Journal of Cancer Supplements, Volume 8, Issue 7, 2010, Page 135, ISSN 1359-6349, http://dx.doi.org/10.1016/ S1359-6349(10)72133-9.

127. E. Kondo, 424 Development of novel cancer cell-selective cell-penetrating peptides for the advanced peptidebased drug delivery system, European Journal of Cancer Supplements, Volume 8, Issue 7, 2010, Page 135, ISSN 1359-6349, http://dx.doi.org/10.1016/S1359-6349(10)72131-5.

128. , Recommended Articles, Journal of Acupuncture and Meridian Studies, Volume 9, Issue 5, 2016, Pages 281284, ISSN 2005-2901, http://dx.doi.org/10.1016/j.jams.2016.10.002.

129. Anil B. Jindal, Sagar S. Bachhav, Padma V. Devarajan, hybrid nano drug delivery system (IHN-DDS) of antiretroviral drug for simultaneous targeting to multiple viral reservoirs: An proof of concept, International Journal of Pharmaceutics, Volume 521, Issue 1, 2017, Pages 196-203, ISSN 0378-5173, http://dx.doi.org/10.1016/ j.ijpharm.2017.02.024.

130. Natalya Rapoport, Physical stimuli-responsive polymeric micelles for anti-cancer drug delivery, Progress in Polymer Science, Volume 32, Issue 8, 2007, Pages 962-990, ISSN 0079-6700, http://dx.doi.org/10.1016/ j.progpolymsci.2007.05.009.

131. Luis Ángel Fernández, Serge Muyldermans, Recent developments in engineering and delivery of protein and antibody therapeutics, Current Opinion in Biotechnology, Volume 22, Issue 6, 2011, Pages 839-842, ISSN 09581669, http://dx.doi.org/10.1016/j.copbio.2011.08.001.

132. Natassa Pippa, Aristides Dokoumetzidis, Costas Demetzos, Panos Macheras, On the ubiquitous presence of fractals and fractal concepts in pharmaceutical sciences: A review, International Journal of Pharmaceutics, Volume 456, Issue 2, 2013, Pages 340-352, ISSN 0378-5173, http://dx.doi.org/10.1016/j.ijpharm.2013.08.087.

133. M. Verreault, D. Strutt, D. Masin, M. Anantha, D. Waterhouse, D.T. Yapp, M.B. Bally, Irinophore CTM, a lipid-based nanoparticulate formulation of irinotecan, is more effective than free irinotecan when used to treat an orthotopic glioblastoma model, Journal of Controlled Release, Volume 158, Issue 1, 2012, Pages 34-43, ISSN 01683659, http://dx.doi.org/10.1016/j.jconrel.2011.09.095. 
134. Parichehr Hassanzadeh, Fatemeh Atyabi, Rassoul Dinarvand, Application of modelling and nanotechnologybased approaches: The emergence of breakthroughs in theranostics of central nervous system disorders, Life Sciences, Volume 182, 2017, Pages 93-103, ISSN 0024-3205, http://dx.doi.org/10.1016/j.lfs.2017.06.001.

135. Senthilkumar Sivanesan, Aaron Tan, Rebecca Jeyaraj, James Lam, Monica Gole, Antonio Hardan, Keyoumars Ashkan, Jayakumar Rajadas, Pharmaceuticals and Stem Cells in Autism Spectrum Disorders: Wishful Thinking?, World Neurosurgery, Volume 98, 2017, Pages 659-672, ISSN 1878-8750, http://dx.doi.org/10.1016/ j.wneu.2016.09.100.

136. R. Phillips, H. Makeen, N. Periasamy, P. Loadman, S. Smye, B. Sleeman, P. Jones, C. Evans, C. Twelves, 427 The development and evaluation of an experimental model for assessing convective fluid flow through multicell layers, European Journal of Cancer Supplements, Volume 8, Issue 7, 2010, Pages 135-136, ISSN 1359-6349, http://dx.doi.org/10.1016/S1359-6349(10)72134-0.

137. Gamze Varan, Cem Varan, Nazlı Erdoğar, A. Atilla Hıncal, Erem Bilensoy, Amphiphilic cyclodextrin nanoparticles, International Journal of Pharmaceutics, 2017, ISSN 0378-5173, http://dx.doi.org/10.1016/ j.ijpharm.2017.06.010.

138. Seyed Moein Moghimi, Zahra Shadi Farhangrazi, Just so stories: The random acts of anti-cancer nanomedicine performance, Nanomedicine: Nanotechnology, Biology and Medicine, Volume 10, Issue 8, 2014, Pages 1661-1666, ISSN 1549-9634, http://dx.doi.org/10.1016/j.nano.2014.04.011.

139. J.C. Soria, C.A. Gomez-Roca, J.A. Ware, A.A. Adjei, R.K. Brachmann, H.J.M. Groen, 421 A Phase Ib study to evaluate the pan-PI3K inhibitor GDC-0941 with paclitaxel and carboplatin with and without bevacizumab in non-small cell lung cancer patients, European Journal of Cancer Supplements, Volume 8, Issue 7, 2010, Page 134, ISSN 1359-6349, http://dx.doi.org/10.1016/S1359-6349(10)72128-5.

140. J. McMurray, J. Klostergaard, E.J. Auzenne, W.S.L. Liao, Z. Lu, P.K. Mandal, R. Ramesh, M. Shanker, A.W. Scott, 422 Targeting the SH2 domain of Stat3 with phosphopeptide mimetic prodrugs leads to tumor growth inhibition and down-regulation of phosphoTyr705 Stat3 and angiogenic pathways, European Journal of Cancer Supplements, Volume 8, Issue 7, 2010, Page 134, ISSN 1359-6349, http://dx.doi.org/10.1016/S13596349(10)72129-7.

141. E. Sans-Serramitjana, E. Fusté, B. Martínez-Garriga, A. Merlos, M. Pastor, J.L. Pedraz, A. Esquisabel, D. Bachiller, T. Vinuesa, M. Viñas, Killing effect of nanoencapsulated colistin sulfate on from cystic fibrosis patients, Journal of Cystic Fibrosis, Volume 15, Issue 5, 2016, Pages 611-618, ISSN 1569-1993, http://dx.doi.org/10.1016/ j.jcf.2015.12.005.

142. Lucas A. Rigo, Cristiane S. Carvalho-Wodarz, Adriana R. Pohlmann, Silvia S. Guterres, Nicole SchneiderDaum, Claus-Michael Lehr, Ruy C.R. Beck, Nanoencapsulation of a glucocorticoid improves barrier function and anti-inflammatory effect on monolayers of pulmonary epithelial cell lines, European Journal of Pharmaceutics and Biopharmaceutics, Volume 119, 2017, Pages 1-10, ISSN 0939-6411, http://dx.doi.org/10.1016/j.ejpb.2017.05.006.

143. Mona Alibolandi, Seyed Mohammad Taghdisi, Pouria Ramezani, Fazileh Hosseini Shamili, Sara Amel Farzad, Khalil Abnous, Mohammad Ramezani, Smart AS1411-aptamer conjugated pegylated PAMAM dendrimer for the superior delivery of camptothecin to colon adenocarcinoma and , International Journal of Pharmaceutics, Volume 519, Issue 1, 2017, Pages 352-364, ISSN 0378-5173, http://dx.doi.org/10.1016/j.ijpharm.2017.01.044.

144. Alexandre Bridoux, Huadong Cui, Evgeny Dyskin, Andreea-Ruxandra Schmitzer, Murat Yalcin, Shaker A. Mousa, Semisynthesis and pharmacological activities of thyroxine analogs: Development of new angiogenesis modulators, Bioorganic \& Medicinal Chemistry Letters, Volume 20, Issue 11, 2010, Pages 3394-3398, ISSN 0960894X, http://dx.doi.org/10.1016/j.bmcl.2010.04.011.

145. Krzysztof Tutaj, Radoslaw Szlazak, Katarzyna Szalapata, Joanna Starzyk, Rafal Luchowski, Wojciech Grudzinski, Monika Osinska-Jaroszuk, Anna Jarosz-Wilkolazka, Agnieszka Szuster-Ciesielska, Wieslaw I. Gruszecki, Amphotericin B-silver hybrid nanoparticles: synthesis, properties and antifungal activity, Nanomedicine: Nanotechnology, Biology and Medicine, Volume 12, Issue 4, 2016, Pages 1095-1103, ISSN 15499634, http://dx.doi.org/10.1016/j.nano.2015.12.378.

146. Palaniselvam Kuppusamy, Mashitah M. Yusoff, Gaanty Pragas Maniam, Natanamurugaraj Govindan, A case study - Regulation and functional mechanisms of cancer cells and control its activity using plants and their derivatives, Journal of Pharmacy Research, Volume 6, Issue 8, 2013, Pages 884-892, ISSN 0974-6943, http://dx.doi.org/10.1016/j.jopr.2013.08.002. 
147. Donald A. Tomalia, International report on nanomedicine in the U.S.A., Nanomedicine: Nanotechnology, Biology and Medicine, Volume 2, Issue 4, 2006, Page 299, ISSN 1549-9634, http://dx.doi.org/10.1016/ j.nano.2006.10.098.

148. Anupa R. Menjoge, Rangaramanujam M. Kannan, Donald A. Tomalia, Dendrimer-based drug and imaging conjugates: design considerations for nanomedical applications, Drug Discovery Today, Volume 15, Issue 5, 2010, Pages 171-185, ISSN 1359-6446, http://dx.doi.org/10.1016/j.drudis.2010.01.009.

149. Karina R. Vega-Villa, Jody K. Takemoto, Jaime A. Yáñez, Connie M. Remsberg, M. Laird Forrest, Neal M. Davies, Clinical toxicities of nanocarrier systems, Advanced Drug Delivery Reviews, Volume 60, Issue 8, 2008, Pages 929-938, ISSN 0169-409X, http://dx.doi.org/10.1016/j.addr.2007.11.007.

150. Shikha Gaur, Yafan Wang, Leo Kretzner, Linling Chen, Terence Yen, Xiwei Wu, Yate-Ching Yuan, Mark Davis, Yun Yen, Pharmacodynamic and pharmacogenomic study of the nanoparticle conjugate of camptothecin CRLX101 for the treatment of cancer, Nanomedicine: Nanotechnology, Biology and Medicine, Volume 10, Issue 7, 2014, Pages 1477-1486, ISSN 1549-9634, http://dx.doi.org/10.1016/j.nano.2014.04.003.

151. Rainer Tietze, Jan Zaloga, Harald Unterweger, Stefan Lyer, Ralf P. Friedrich, Christina Janko, Marina Pöttler, Stephan Dürr, Christoph Alexiou, Magnetic nanoparticle-based drug delivery for cancer therapy, Biochemical and Biophysical Research Communications, Volume 468, Issue 3, 2015, Pages 463-470, ISSN 0006-291X, http://dx.doi.org/10.1016/j.bbrc.2015.08.022.

152. Alex Schwengber, Héctor J. Prado, Darío A. Zilli, Pablo R. Bonelli, Ana L. Cukierman, Carbon nanotubes buckypapers for potential transdermal drug delivery, Materials Science and Engineering: C, Volume 57, 2015, Pages 7-13, ISSN 0928-4931, http://dx.doi.org/10.1016/j.msec.2015.07.030.

153. Piya Adhikari, Paulami Pal, Anup Kr. Das, Subhabrata Ray, Arpita Bhattacharjee, Bhaskar Mazumder, NANO LIPID-DRUG CONJUGATE: AN INTEGRATED REVIEW, International Journal of Pharmaceutics, 2017, ISSN 0378-5173, http://dx.doi.org/10.1016/j.ijpharm.2017.07.039.

154. Janos Szebeni, Gert Storm, Complement activation as a bioequivalence issue relevant to the development of generic liposomes and other nanoparticulate drugs, Biochemical and Biophysical Research Communications, Volume 468, Issue 3, 2015, Pages 490-497, ISSN 0006-291X, http://dx.doi.org/10.1016/j.bbrc.2015.06.177.

155. Kaihua Chen, Jiancheng Guan, A bibliometric investigation of research performance in emerging nanobiopharmaceuticals, Journal of Informetrics, Volume 5, Issue 2, 2011, Pages 233-247, ISSN 1751-1577, http://dx.doi.org/10.1016/j.joi.2010.10.007.

156. Raquel Requejo-Aguilar, Ana Alastrue-Agudo, Marta Cases-Villar, Eric Lopez-Mocholi, Richard England, María J. Vicent, Victoria Moreno-Manzano, Combined polymer-curcumin conjugate and ependymal progenitor/stem cell treatment enhances spinal cord injury functional recovery, Biomaterials, Volume 113, 2017, Pages 18-30, ISSN 0142-9612, http://dx.doi.org/10.1016/j.biomaterials.2016.10.032.

157. Dmytro Golyshkin, Nazarii Kobyliak, Oleksandr Virchenko, Tetyana Falalyeyeva, Tetyana Beregova, Lyudmyla Ostapchenko, Martin Caprnda, Lubomir Skladany, Radka Opatrilova, Luis Rodrigo, Peter Kruzliak, Alexandr Shcherbokov, Mykola Spivak, Nanocrystalline cerium dioxide efficacy for prophylaxis of erosive and ulcerative lesions in the gastric mucosa of rats induced by stress, Biomedicine \& Pharmacotherapy, Volume 84, 2016, Pages 1383-1392, ISSN 0753-3322, http://dx.doi.org/10.1016/j.biopha.2016.10.060.

158. Aleksandra Szulc, Lukasz Pulaski, Dietmar Appelhans, Brigitte Voit, Barbara Klajnert-Maculewicz, Sugarmodified poly(propylene imine) dendrimers as drug delivery agents for cytarabine to overcome drug resistance, International Journal of Pharmaceutics, Volume 513, Issue 1, 2016, Pages 572-583, ISSN 0378-5173, http://dx.doi.org/10.1016/j.ijpharm.2016.09.063.

159. Paula S. Haddad, Tatiana M. Martins, Lília D'Souza-Li, Li M. Li, Konradin Metze, Randall L. Adam, Marcelo Knobel, Daniela Zanchet, Structural and morphological investigation of magnetic nanoparticles based on iron oxides for biomedical applications, Materials Science and Engineering: C, Volume 28, Issue 4, 2008, Pages 489-494, ISSN 0928-4931, http://dx.doi.org/10.1016/j.msec.2007.04.014.

160. Serge Mignani, Saïd El Kazzouli, Mosto Bousmina, Jean-Pierre Majoral, Dendrimer space concept for innovative nanomedicine: A futuristic vision for medicinal chemistry, Progress in Polymer Science, Volume 38, Issue 7, 2013, Pages 993-1008, ISSN 0079-6700, http://dx.doi.org/10.1016/j.progpolymsci.2013.03.003.

161. Mike A.W. Eaton, Laurent Levy, Olivier M.A. Fontaine, Delivering nanomedicines to patients: A practical guide, Nanomedicine: Nanotechnology, Biology and Medicine, Volume 11, Issue 4, 2015, Pages 983-992, ISSN 1549-9634, http://dx.doi.org/10.1016/j.nano.2015.02.004. 
162. Giovanna Lollo, Pablo Hervella, Pilar Calvo, Pablo Avilés, Maria Jose Guillén, Marcos Garcia-Fuentes, Maria José Alonso, Dolores Torres, Enhanced therapeutic efficacy of plitidepsin-loaded nanocapsules decorated with a new poly-aminoacid-PEG derivative, International Journal of Pharmaceutics, Volume 483, Issue 1, 2015, Pages 212-219, ISSN 0378-5173, http://dx.doi.org/10.1016/j.ijpharm.2015.02.028.

163. N. Thompson, M. Ahn, G. Chessari, K. Hearn, C.N. Johnson, J. Lewis, G. Ward, P. Williams, A. Woolford, 85 Characterization of a Potent XIAP and CIAP1 Dual Antagonist in Models of Melanoma and Leukemia, European Journal of Cancer, Volume 48, 2012, Page 27, ISSN 0959-8049, http://dx.doi.org/10.1016/S0959-8049(12)71883-X.

164. Graphical Abstracts, Journal of Fluorine Chemistry, Volume 174, 2015, Pages vii-xii, ISSN 0022-1139, http://dx.doi.org/10.1016/S0022-1139(15)00114-1.

165. Eameema Muntimadugu, Nagavendra Kommineni, Wahid Khan, Exploring the Potential of Nanotherapeutics in Targeting Tumor Microenvironment for Cancer Therapy, Pharmacological Research, 2017, ISSN 1043-6618, http://dx.doi.org/10.1016/j.phrs.2017.05.010.

166. Marianna Foldvari, Mukasa Bagonluri, Carbon nanotubes as functional excipients for nanomedicines: II. Drug delivery and biocompatibility issues, Nanomedicine: Nanotechnology, Biology and Medicine, Volume 4, Issue 3, 2008, Pages 183-200, ISSN 1549-9634, http://dx.doi.org/10.1016/j.nano.2008.04.003.

167. , Graphical Abstracts, Journal of Fluorine Chemistry, Volume 171, 2015, Pages vii-xiii, ISSN 0022-1139, http://dx.doi.org/10.1016/S0022-1139(15)00032-9.

168. J.S. Riley, P.G. Johnston, D.B. Longley, 83 Investigation of Post-translational Modifications of c-FLIP, European Journal of Cancer, Volume 48, 2012, Page 27, ISSN 0959-8049, http://dx.doi.org/10.1016/S09598049(12)71881-6.

169. Elisabete Fernandes, José Alexandre Ferreira, Peixoto Andreia, Lima Luís, Sérgio Barroso, Bruno Sarmento, Lúcio Lara Santos, New trends in guided nanotherapies for digestive cancers: A systematic review, Journal of Controlled Release, Volume 209, 2015, Pages 288-307, ISSN 0168-3659, http://dx.doi.org/10.1016/ j.jconrel.2015.05.003.

170. Neelesh Kumar Mehra, Srinath Palakurthi, Interactions between carbon nanotubes and bioactives: a drug delivery perspective, Drug Discovery Today, Volume 21, Issue 4, 2016, Pages 585-597, ISSN 1359-6446, http://dx.doi.org/10.1016/j.drudis.2015.11.011.

171. Serge Mignani, Scot Huber, Helena Tomás, João Rodrigues, Jean-Pierre Majoral, Why and how have drug discovery strategies in pharma changed? What are the new mindsets?, Drug Discovery Today, Volume 21, Issue 2, 2016, Pages 239-249, ISSN 1359-6446, http://dx.doi.org/10.1016/j.drudis.2015.09.007.

172. Elenaz Naderkhani, Astrid Erber, Nataša Škalko-Basnet, Gøril Eide Flaten, Improved Permeability of Acyclovir: Optimization of Mucoadhesive Liposomes Using the Phospholipid Vesicle-Based Permeation Assay, Journal of Pharmaceutical Sciences, Volume 103, Issue 2, 2014, Pages 661-668, ISSN 0022-3549, http://dx.doi.org/10.1002/jps.23845.

173. David Newton, Literature listing, World Patent Information, Volume 35, Issue 4, 2013, Pages 352-357, ISSN 0172-2190, http://dx.doi.org/10.1016/j.wpi.2013.06.006.

174. Ichio Aoki, Misao Yoneyama, Jun Hirose, Yuzuru Minemoto, Takayoshi Koyama, Daisuke Kokuryo, Rumiana Bakalova, Shuhei Murayama, Tsuneo Saga, Sadahito Aoshima, Yukihito Ishizaka, Kenji Kono, Thermoactivatable polymer-grafted liposomes for low-invasive image-guided chemotherapy, Translational Research, Volume 166, Issue 6, 2015, Pages 660-673.e1, ISSN 1931-5244, http://dx.doi.org/10.1016/ j.trsl.2015.07.009.

175. K.B. Ita, Transdermal drug delivery: progress and challenges, Journal of Drug Delivery Science and Technology, Volume 24, Issue 3, 2014, Pages 245-250, ISSN 1773-2247, http://dx.doi.org/10.1016/S17732247(14)50041-X.

176. Je-Ruei Liu, Guo-Feng Chen, Hui-Nung Shih, Ping-Chung Kuo, Enhanced antioxidant bioactivity of (Danshen) products prepared using nanotechnology, Phytomedicine, Volume 15, Issue 1, 2008, Pages 23-30, ISSN 0944-7113, http://dx.doi.org/10.1016/j.phymed.2007.11.012.

177. Surya K. Mallapragada, Timothy M. Brenza, JoEllyn M. McMillan, Balaji Narasimhan, Donald S. Sakaguchi, Anup D. Sharma, Svitlana Zbarska, Howard E. Gendelman, Enabling nanomaterial, nanofabrication and cellular technologies for nanoneuromedicines, Nanomedicine: Nanotechnology, Biology and Medicine, Volume 11, Issue 3, 2015, Pages 715-729, ISSN 1549-9634, http://dx.doi.org/10.1016/j.nano.2014.12.013. 
178. Carina Peres, Ana I. Matos, João Conniot, Vanessa Sainz, Eva Zupančič, Joana M. Silva, Luís Graça, Rogério Sá Gaspar, Véronique Préat, Helena F. Florindo, Poly(lactic acid)-based particulate systems are promising tools for immune modulation, Acta Biomaterialia, Volume 48, 2017, Pages 41-57, ISSN 1742-7061, http://dx.doi.org/10.1016/j.actbio.2016.11.012.

179. A.J. Ferreira, J. Cemlyn-Jones, C. Robalo Cordeiro, Nanoparticles, nanotechnology and pulmonary nanotoxicology, Revista Portuguesa de Pneumologia (English Edition), Volume 19, Issue 1, 2013, Pages 28-37, ISSN 2173-5115, http://dx.doi.org/10.1016/j.rppnen.2013.01.004.

180. A.J. Ferreira, J. Cemlyn-Jones, C. Robalo Cordeiro, Nanoparticles, nanotechnology and pulmonary nanotoxicology, Revista Portuguesa de Pneumologia, Volume 19, Issue 1, 2013, Pages 28-37, ISSN 0873-2159, http://dx.doi.org/10.1016/j.rppneu.2012.09.003.

181. Aurelio Salerno, Concepción Domingo Pascual, Bio-based polymers, supercritical fluids and tissue engineering, Process Biochemistry, Volume 50, Issue 5, 2015, Pages 826-838, ISSN 1359-5113, http://dx.doi.org/10.1016/ j.procbio.2015.02.009.

182. Betty Tyler, David Gullotti, Antonella Mangraviti, Tadanobu Utsuki, Henry Brem, Polylactic acid (PLA) controlled delivery carriers for biomedical applications, Advanced Drug Delivery Reviews, Volume 107, 2016, Pages 163-175, ISSN 0169-409X, http://dx.doi.org/10.1016/j.addr.2016.06.018.

183. Daniela Iannazzo, Alessandro Pistone, Signorino Galvagno, Stefania Ferro, Laura De Luca, Anna Maria Monforte, Tatiana Da Ros, Caroline Hadad, Maurizio Prato, Christophe Pannecouque, Synthesis and anti-HIV activity of carboxylated and drug-conjugated multi-walled carbon nanotubes, Carbon, Volume 82, 2015, Pages 548-561, ISSN 0008-6223, http://dx.doi.org/10.1016/j.carbon.2014.11.007.

184. Anita Jemec, Petar Djinović, Tatjana Tišler, Albin Pintar, Effects of four CeO nanocrystalline catalysts on early-life stages of zebrafish and crustacean, Journal of Hazardous Materials, Volume 219, 2012, Pages 213-220, ISSN 0304-3894, http://dx.doi.org/10.1016/j.jhazmat.2012.03.080.

185. H.L. Chen, W.T. Tai, C.W. Shiau, C.Y. Liu, C.S. Lin, A.L. Cheng, P.J. Chen, K.F. Chen, 82 Sorafenib and Its Derivative SC-59 Induces Autophagy in Hepatocellular Carcinoma Through SHP-1 Dependent Inhibition of STAT3, European Journal of Cancer, Volume 48, 2012, Pages 26-27, ISSN 0959-8049, http://dx.doi.org/10.1016/ S0959-8049(12)71880-4.

186. N. Lütscher, S. Hönes, M. Grubert, M.E. Scheulen, R.A. Hilger, 86 Antitumoral Activity of a New Class of Triazenes, European Journal of Cancer, Volume 48, 2012, Pages 27-28, ISSN 0959-8049, http://dx.doi.org/ 10.1016/S0959-8049(12)71884-1.

187. Chun-Woong Park, Xiaojian Li, Frederick G. Vogt, Don Hayes, Joseph B. Zwischenberger, Eun-Seok Park, Heidi M. Mansour, Advanced spray-dried design, physicochemical characterization, and aerosol dispersion performance of vancomycin and clarithromycin multifunctional controlled release particles for targeted respiratory delivery as dry powder inhalation aerosols, International Journal of Pharmaceutics, Volume 455, Issue 1, 2013, Pages 374-392, ISSN 0378-5173, http://dx.doi.org/10.1016/j.ijpharm.2013.06.047.

188. H. Huang, Q. Yuan, J.S. Shah, R.D.K. Misra, A new family of folate-decorated and carbon nanotube-mediated drug delivery system: Synthesis and drug delivery response, Advanced Drug Delivery Reviews, Volume 63, Issue 14, 2011, Pages 1332-1339, ISSN 0169-409X, http://dx.doi.org/10.1016/j.addr.2011.04.001.

189. D. Depan, J. Shah, R.D.K. Misra, Controlled release of drug from folate-decorated and graphene mediated drug delivery system: Synthesis, loading efficiency, and drug release response, Materials Science and Engineering: C, Volume 31, Issue 7, 2011, Pages 1305-1312, ISSN 0928-4931, http://dx.doi.org/10.1016/j.msec.2011.04.010.

190. Shutao Guo, Leaf Huang, Nanoparticles containing insoluble drug for cancer therapy, Biotechnology Advances, Volume 32, Issue 4, 2014, Pages 778-788, ISSN 0734-9750, http://dx.doi.org/10.1016/j.biotechadv.2013.10.002.

191. Ruth Duncan, Polymer therapeutics as nanomedicines: new perspectives, Current Opinion in Biotechnology, Volume 22, Issue 4, 2011, Pages 492-501, ISSN 0958-1669, http://dx.doi.org/10.1016/j.copbio.2011.05.507.

192. Nor Azwadi Che Sidik, Muhammad Noor Afiq Witri Muhammad Yazid, Syahrullail Samion, Mohamad Nor Musa, Rizalman Mamat, Latest development on computational approaches for nanofluid flow modeling: NavierStokes based multiphase models, International Communications in Heat and Mass Transfer, Volume 74, 2016, Pages 114-124, ISSN 0735-1933, http://dx.doi.org/10.1016/j.icheatmasstransfer.2016.03.007.

193. Q. Yuan, S. Hein, R.D.K. Misra, New generation of chitosan-encapsulated ZnO quantum dots loaded with drug: Synthesis, characterization and in vitro drug delivery response, Acta Biomaterialia, Volume 6, Issue 7, 2010, Pages 2732-2739, ISSN 1742-7061, http://dx.doi.org/10.1016/j.actbio.2010.01.025. 
194. Weiwei He, Yitong Liu, Wayne G. Wamer, Jun-Jie Yin, Electron spin resonance spectroscopy for the study of nanomaterial-mediated generation of reactive Oxygen species, Journal of Food and Drug Analysis, Volume 22, Issue 1, 2014, Pages 49-63, ISSN 1021-9498, http://dx.doi.org/10.1016/j.jfda.2014.01.004.

195. Jing An, Yuqiang Gou, Chunxia Yang, Fangdi Hu, Chunming Wang, Synthesis of a biocompatible gelatin functionalized graphene nanosheets and its application for drug delivery, Materials Science and Engineering: C, Volume 33, Issue 5, 2013, Pages 2827-2837, ISSN 0928-4931, http://dx.doi.org/10.1016/j.msec.2013.03.008.

196. Samantha A. Meenach, Kimberly W. Anderson, J. Zach Hilt, Ronald C. McGarry, Heidi M. Mansour, Characterization and aerosol dispersion performance of advanced spray-dried chemotherapeutic PEGylated phospholipid particles for dry powder inhalation delivery in lung cancer, European Journal of Pharmaceutical Sciences, Volume 49, Issue 4, 2013, Pages 699-711, ISSN 0928-0987, http://dx.doi.org/10.1016/j.ejps.2013.05.012.

197. Richard M. England, Esther Masiá, Vanessa Giménez, Rut Lucas, María J. Vicent, Polyacetal-stilbene conjugates - The first examples of polymer therapeutics for the inhibition of HIF-1 in the treatment of solid tumours, Journal of Controlled Release, Volume 164, Issue 3, 2012, Pages 314-322, ISSN 0168-3659, http://dx.doi.org/10.1016/j.jconrel.2012.08.017.

198. Natassa Pippa, Maria Merkouraki, Stergios Pispas, Costas Demetzos, DPPC:MPOx chimeric advanced Drug Delivery nano Systems (chi-aDDnSs): Physicochemical and structural characterization, stability and drug release studies, International Journal of Pharmaceutics, Volume 450, Issue 1, 2013, Pages 1-10, ISSN 0378-5173, http://dx.doi.org/10.1016/j.ijpharm.2013.03.052.

199. Patrick Boisseau, Bertrand Loubaton, Nanomedicine, nanotechnology in medicine, Comptes Rendus Physique, Volume 12, Issue 7, 2011, Pages 620-636, ISSN 1631-0705, http://dx.doi.org/10.1016/j.crhy.2011.06.001.

200. Oksana Petrichenko, Martins Rucins, Aleksandra Vezane, Irena Timofejeva, Arkadij Sobolev, Brigita Cekavicus, Karlis Pajuste, Mara Plotniece, Marina Gosteva, Tatjana Kozlovska, Aiva Plotniece, Studies of the physicochemical and structural properties of self-assembling cationic pyridine derivatives as gene delivery agents, Chemistry and Physics of Lipids, Volume 191, 2015, Pages 25-37, ISSN 0009-3084, http://dx.doi.org/10.1016/ j.chemphyslip.2015.08.005.

201. Alicia Rodríguez-Gascón, Ana del Pozo-Rodríguez, Arantxazu Isla, María Angeles Solinís, Vaginal gene therapy, Advanced Drug Delivery Reviews, Volume 92, 2015, Pages 71-83, ISSN 0169-409X, http://dx.doi.org/10.1016/ j.addr.2015.07.002.

202. Heico J. Frima, Cristina Gabellieri, Maj-Inger Nilsson, Drug delivery research in the European Union's Seventh Framework Programme for Research, Journal of Controlled Release, Volume 161, Issue 2, 2012, Pages 409-415, ISSN 0168-3659, http://dx.doi.org/10.1016/j.jconrel.2012.01.044.

203. Murali M. Yallapu, Neeraj Chauhan, Shadi F. Othman, Vahid Khalilzad-Sharghi, Mara C. Ebeling, Sheema Khan, Meena Jaggi, Subhash C. Chauhan, Implications of protein corona on physico-chemical and biological properties of magnetic nanoparticles, Biomaterials, Volume 46, 2015, Pages 1-12, ISSN 0142-9612, http://dx.doi.org/10.1016/j.biomaterials.2014.12.045.

204. Jinghua Duan, Heidi M. Mansour, Yangde Zhang, Xingming Deng, Yuxiang Chen, Jiwei Wang, Yifeng Pan, Jinfeng Zhao, Reversion of multidrug resistance by co-encapsulation of doxorubicin and curcumin in chitosan/poly(butyl cyanoacrylate) nanoparticles, International Journal of Pharmaceutics, Volume 426, Issue 1, 2012, Pages 193-201, ISSN 0378-5173, http://dx.doi.org/10.1016/j.ijpharm.2012.01.020.

205. Roman A. Perez, Hae-Won Kim, Core-shell designed scaffolds for drug delivery and tissue engineering, Acta Biomaterialia, Volume 21, 2015, Pages 2-19, ISSN 1742-7061, http://dx.doi.org/10.1016/j.actbio.2015.03.013.

206. Luca Costantino, Diana Boraschi, Is there a clinical future for polymeric nanoparticles as brain-targeting drug delivery agents?, Drug Discovery Today, Volume 17, Issue 7, 2012, Pages 367-378, ISSN 1359-6446, http://dx.doi.org/10.1016/j.drudis.2011.10.028.

207. Chiming Wei, Yuri L. Lyubchenko, Hamid Ghandehari, Justin Hanes, Kathleen J. Stebe, Hai-Quan Mao, Donald T. Haynie, Donald A. Tomalia, Marianna Foldvari, Nancy Monteiro-Riviere, Petia Simeonova, Shuming Nie, Hidezo Mori, Susan P. Gilbert, David Needham, New technology and clinical applications of nanomedicine: Highlights of the second annual meeting of the American Academy of Nanomedicine (Part I), Nanomedicine: Nanotechnology, Biology and Medicine, Volume 2, Issue 4, 2006, Pages 253-263, ISSN 1549-9634, http://dx.doi.org/10.1016/j.nano.2006.11.001. 
208. James S. Murday, Richard W. Siegel, Judith Stein, J. Fraser Wright, Translational nanomedicine: status assessment and opportunities, Nanomedicine: Nanotechnology, Biology and Medicine, Volume 5, Issue 3, 2009, Pages 251-273, ISSN 1549-9634, http://dx.doi.org/10.1016/j.nano.2009.06.001.

209. Nishu Dixit, Kumar Vaibhav, Ravi Shankar Pandey, Upendra Kumar Jain, Om Prakash Katare, Anju Katyal, Jitender Madan, Improved cisplatin delivery in cervical cancer cells by utilizing folate-grafted non-aggregated gelatin nanoparticles, Biomedicine \& Pharmacotherapy, Volume 69, 2015, Pages 1-10, ISSN 0753-3322, http://dx.doi.org/10.1016/j.biopha.2014.10.016.

210. Hareesh B. Nair, Bokyung Sung, Vivek R. Yadav, Ramaswamy Kannappan, Madan M. Chaturvedi, Bharat B. Aggarwal, Delivery of antiinflammatory nutraceuticals by nanoparticles for the prevention and treatment of cancer, Biochemical Pharmacology, Volume 80, Issue 12, 2010, Pages 1833-1843, ISSN 0006-2952, http://dx.doi.org/10.1016/j.bcp.2010.07.021.

211. Raj Bawa, S.R. Bawa, Stephen B. Maebius, Ted Flynn, Chiming Wei, Protecting new ideas and inventions in nanomedicine with patents, Nanomedicine: Nanotechnology, Biology and Medicine, Volume 1, Issue 2, 2005, Pages 150-158, ISSN 1549-9634, http://dx.doi.org/10.1016/j.nano.2005.03.009.

212. Samad Mussa Farkhani, Alireza Valizadeh, Hadi Karami, Samane Mohammadi, Nasrin Sohrabi, Fariba Badrzadeh, Cell penetrating peptides: Efficient vectors for delivery of nanoparticles, nanocarriers, therapeutic and diagnostic molecules, Peptides, Volume 57, 2014, Pages 78-94, ISSN 0196-9781. http://dx.doi.org/10.1016/ j.peptides.2014.04.015.

213. Graphical Abstracts, Journal of Fluorine Chemistry, Volume 168, 2014, Pages v-xv, ISSN 0022-1139, http://dx.doi.org/10.1016/S0022-1139(14)00353-4.

214. Ratnesh Lal, Morton F. Arnsdorf, Multidimensional atomic force microscopy for drug discovery: A versatile tool for defining targets, designing therapeutics and monitoring their efficacy, Life Sciences, Volume 86, Issue 15, 2010, Pages 545-562, ISSN 0024-3205, http://dx.doi.org/10.1016/j.lfs.2009.02.030.

215. Fredrik Hacklin, Christian Marxt, Fritz Fahrni, Coevolutionary cycles of convergence: An extrapolation from the ICT industry, Technological Forecasting and Social Change, Volume 76, Issue 6, 2009, Pages 723-736, ISSN 0040-1625, http://dx.doi.org/10.1016/j.techfore.2009.03.003.

216. Alberto A. Gabizon, Yogita Patil, Ninh M. La-Beck, New insights and evolving role of pegylated liposomal doxorubicin in cancer therapy, Drug Resistance Updates, Volume 29, 2016, Pages 90-106, ISSN 1368-7646, http://dx.doi.org/10.1016/j.drup.2016.10.003.

217. Jianxiang Zhang, Peter X. Ma, Cyclodextrin-based supramolecular systems for drug delivery: Recent progress and future perspective, Advanced Drug Delivery Reviews, Volume 65, Issue 9, 2013, Pages 1215-1233, ISSN 0169409X, http://dx.doi.org/10.1016/j.addr.2013.05.001.

218. Ž. Vanić, N. Škalko-Basnet, Mucosal nanosystems for improved topical drug delivery: vaginal route of administration, Journal of Drug Delivery Science and Technology, Volume 24, Issue 5, 2014, Pages 435-444, ISSN 1773-2247, http://dx.doi.org/10.1016/S1773-2247(14)50085-8.

219. Rutledge Ellis-Behnke, Nano Neurology and the Four P's of Central Nervous System Regeneration: Preserve, Permit, Promote, Plasticity, Medical Clinics of North America, Volume 91, Issue 5, 2007, Pages 937-962, ISSN 0025-7125, http://dx.doi.org/10.1016/j.mcna.2007.04.005.

220. Kale Mohana Raghava Srivalli, Brahmeshwar Mishra, Drug nanocrystals: A way toward scale-up, Saudi Pharmaceutical Journal, Volume 24, Issue 4, 2016, Pages 386-404, ISSN 1319-0164, http://dx.doi.org/10.1016/ j.jsps.2014.04.007.

221. Eva-Maria Collnot, Hussain Ali, Claus-Michael Lehr, Nano- and microparticulate drug carriers for targeting of the inflamed intestinal mucosa, Journal of Controlled Release, Volume 161, Issue 2, 2012, Pages 235-246, ISSN 0168-3659, http://dx.doi.org/10.1016/j.jconrel.2012.01.028.

222. Joshua J. Rychak, Jonathan R. Lindner, Klaus Ley, Alexander L. Klibanov, Deformable gas-filled microbubbles targeted to P-selectin, Journal of Controlled Release, Volume 114, Issue 3, 2006, Pages 288-299, ISSN 0168-3659, http://dx.doi.org/10.1016/j.jconrel.2006.06.008.

223. Cezary Watala, Kamil Karolczak, Hassan Kassassir, Marcin Talar, Tomasz Przygodzki, Katarzyna Maczynska, Magdalena Labieniec-Watala, How do the full-generation poly(amido)amine (PAMAM) dendrimers activate blood platelets? Activation of circulating platelets and formation of "fibrinogen aggregates" in the presence of polycations, International Journal of Pharmaceutics, Volume 503, Issue 1, 2016, Pages 247-261, ISSN 0378-5173, http://dx.doi.org/10.1016/j.ijpharm.2015.08.073. 
224. M.S. Palombo, Y. Singh, P.J. Sinko, Prodrug and conjugate drug delivery strategies for improving HIV/AIDS therapy, Journal of Drug Delivery Science and Technology, Volume 19, Issue 1, 2009, Pages 3-14, ISSN 1773-2247, http://dx.doi.org/10.1016/S1773-2247(09)50001-9.

225. , Table of Contents, Nanomedicine: Nanotechnology, Biology and Medicine, Volume 7, Issue 4, 2011, Pages A4A5, ISSN 1549-9634, http://dx.doi.org/10.1016/S1549-9634(11)00192-4.

226. Andriy Kuzmov, Tamara Minko, Nanotechnology approaches for inhalation treatment of lung diseases, Journal of Controlled Release, Volume 219, 2015, Pages 500-518, ISSN 0168-3659, http://dx.doi.org/10.1016/ j.jconrel.2015.07.024.

227. Yolanda Diebold, Margarita Calonge, Applications of nanoparticles in ophthalmology, Progress in Retinal and Eye Research, Volume 29, Issue 6, 2010, Pages 596-609, ISSN 1350-9462, http://dx.doi.org/10.1016/ j.preteyeres.2010.08.002.

228. Ramazan Bal, Gaffari Türk, Mehmet Tuzcu, Okkes Yilmaz, Ibrahim Ozercan, Tuncay Kuloglu, Seyfettin Gür, Victor S. Nedzvetsky, Artem A. Tykhomyrov, Grigory V. Andrievsky, Giyasettin Baydas, Mustafa Naziroglu, Protective effects of nanostructures of hydrated $\mathrm{C}$ fullerene on reproductive function in streptozotocin-diabetic male rats, Toxicology, Volume 282, Issue 3, 2011, Pages 69-81, ISSN 0300-483X, http://dx.doi.org/10.1016/ j.tox.2010.12.003.

229. Dhruba J. Bharali, Shaker A. Mousa, Emerging nanomedicines for early cancer detection and improved treatment: Current perspective and future promise, Pharmacology \& Therapeutics, Volume 128, Issue 2, 2010, Pages 324-335, ISSN 0163-7258, http://dx.doi.org/10.1016/j.pharmthera.2010.07.007.

230. Sandipan Ray, Harini Chandra, Sanjeeva Srivastava, Nanotechniques in proteomics: Current status, promises and challenges, Biosensors and Bioelectronics, Volume 25, Issue 11, 2010, Pages 2389-2401, ISSN 0956-5663, http://dx.doi.org/10.1016/j.bios.2010.04.010.

231. B. Mishra, Bhavesh B. Patel, Sanjay Tiwari, Colloidal nanocarriers: a review on formulation technology, types and applications toward targeted drug delivery, Nanomedicine: Nanotechnology, Biology and Medicine, Volume 6, Issue 1, 2010, Pages 9-24, ISSN 1549-9634, http://dx.doi.org/10.1016/j.nano.2009.04.008.

232. Contents, Nanomedicine: Nanotechnology, Biology and Medicine, Volume 4, Issue 4, 2008, Pages A3-A4, ISSN 1549-9634, http://dx.doi.org/10.1016/S1549-9634(08)00178-0.

233. Vladimir Torchilin, Multifunctional and stimuli-sensitive pharmaceutical nanocarriers, European Journal of Pharmaceutics and Biopharmaceutics, Volume 71, Issue 3, 2009, Pages 431-444, ISSN 0939-6411, http://dx.doi.org/10.1016/j.ejpb.2008.09.026.

234. Francesca A. Cupaioli, Fabio A. Zucca, Diana Boraschi, Luigi Zecca, Engineered nanoparticles. How brain friendly is this new guest?, Progress in Neurobiology, Volume 119, 2014, Pages 20-38, ISSN 0301-0082, http://dx.doi.org/10.1016/j.pneurobio.2014.05.002.

235. Alejandro Sosnik, Angel M. Carcaboso, Nanomedicines in the future of pediatric therapy, Advanced Drug Delivery Reviews, Volume 73, 2014, Pages 140-161, ISSN 0169-409X, http://dx.doi.org/10.1016/ j.addr.2014.05.004.

236. Table of Contents, Nanomedicine: Nanotechnology, Biology and Medicine, Volume 10, Issue 1, 2014, Pages A4A7, ISSN 1549-9634, http://dx.doi.org/10.1016/S1549-9634(13)00599-6.

237. Jiancheng Guan, Qingjun Zhao, The impact of university-industry collaboration networks on innovation in nanobiopharmaceuticals, Technological Forecasting and Social Change, Volume 80, Issue 7, 2013, Pages 12711286, ISSN 0040-1625, http://dx.doi.org/10.1016/j.techfore.2012.11.013.

238. Lisa C. Du Toit, Thirumala Govender, Trevor Carmichael, Pradeep Kumar, Yahya E. Choonara, Viness Pillay, Design of an Anti-Inflammatory Composite Nanosystem and Evaluation of Its Potential for Ocular Drug Delivery, Journal of Pharmaceutical Sciences, Volume 102, Issue 8, 2013, Pages 2780-2805, ISSN 0022-3549, http://dx.doi.org/10.1002/jps.23650.

239. Emerging Fields, Free Radical Biology and Medicine, Volume 43, 2007, Pages S67-S74, ISSN 0891-5849, http://dx.doi.org/10.1016/j.freeradbiomed.2007.10.018.

240. Xue-Qing Zhang, Xiaoyang Xu, Nicolas Bertrand, Eric Pridgen, Archana Swami, Omid C. Farokhzad, Interactions of nanomaterials and biological systems: Implications to personalized nanomedicine, Advanced Drug Delivery Reviews, Volume 64, Issue 13, 2012, Pages 1363-1384, ISSN 0169-409X, http://dx.doi.org/10.1016/ j.addr.2012.08.005. 
241. Arunachalam Muthaiyan, Alya Limayem, Steven C. Ricke, Antimicrobial strategies for limiting bacterial contaminants in fuel bioethanol fermentations, Progress in Energy and Combustion Science, Volume 37, Issue 3, 2011, Pages 351-370, ISSN 0360-1285, http://dx.doi.org/10.1016/j.pecs.2010.06.005.

242. Scientific Programme - Details, European Journal of Cancer Supplements, Volume 8, Issue 7, 2010, Pages xxivlxvi, ISSN 1359-6349, http://dx.doi.org/10.1016/S1359-6349(10)71697-9.

243., Subject Index, European Journal of Cancer Supplements, Volume 8, Issue 7, 2010, Pages 233-243, ISSN 13596349, http://dx.doi.org/10.1016/S1359-6349(10)72373-9.

244. Ruth Duncan, Development of HPMA copolymer-anticancer conjugates: Clinical experience and lessons learnt, Advanced Drug Delivery Reviews, Volume 61, Issue 13, 2009, Pages 1131-1148, ISSN 0169-409X, http://dx.doi.org/10.1016/j.addr.2009.05.007.

245. R. Palao-Suay, L.G. Gómez-Mascaraque, M.R. Aguilar, B. Vázquez-Lasa, J. San Román, Self-assembling polymer systems for advanced treatment of cancer and inflammation, Progress in Polymer Science, Volume 53, 2016, Pages 207-248, ISSN 0079-6700, http://dx.doi.org/10.1016/j.progpolymsci.2015.07.005.

246. K. John Morrow, Raj Bawa, Chiming Wei, Recent Advances in Basic and Clinical Nanomedicine, Medical Clinics of North America, Volume 91, Issue 5, 2007, Pages 805-843, ISSN 0025-7125, http://dx.doi.org/10.1016/ j.mena.2007.05.009.

247. Tissue/Cell Targets and Reactions, Free Radical Biology and Medicine, Volume 41, 2006, Pages S144-S154, ISSN 0891-5849, http://dx.doi.org/10.1016/j.freeradbiomed.2006.10.015.

248. Inflammation, Free Radical Biology and Medicine, Volume 41, 2006, Pages S68-S78, ISSN 0891-5849, http://dx.doi.org/10.1016/j.freeradbiomed.2006.10.008.

249. Vinay Deep Punetha, Sravendra Rana, Hye Jin Yoo, Alok Chaurasia, James T. McLeskey, Madeshwaran Sekkarapatti Ramasamy, Nanda Gopal Sahoo, Jae Whan Cho, Functionalization of carbon nanomaterials for advanced polymer nanocomposites: A comparison study between CNT and graphene, Progress in Polymer Science, Volume 67, 2017, Pages 1-47, ISSN 0079-6700, http://dx.doi.org/10.1016/j.progpolymsci.2016.12.010.

250. Antioxidants, Nutrition \& Health, Free Radical Biology and Medicine, Volume 41, 2006, Pages S18-S31, ISSN 0891-5849, http://dx.doi.org/10.1016/j.freeradbiomed.2006.10.002.

251. Scientific Programme - Proffered Papers, European Journal of Cancer, Volume 49, 2013, Pages S97-S153, ISSN 0959-8049, http://dx.doi.org/10.1016/S0959-8049(13)70060-1.

252. Subject Index, European Journal of Cancer, Volume 49, 2013, Pages S975-S1028, ISSN 0959-8049, http://dx.doi.org/10.1016/S0959-8049(13)70067-4.

253. Goldschmidt Abstracts 2010 - H, Geochimica et Cosmochimica Acta, Volume 74, Issue 12, 2010, Pages A369A440, ISSN 0016-7037, http://dx.doi.org/10.1016/j.gca.2010.04.033.

254. Sivakumar Manickam, Editorial Note, Ultrasonics Sonochemistry, Volume 35, 2017, Pages 529-530, ISSN 13504177, http://dx.doi.org/10.1016/j.ultsonch.2016.06.028.

255. Juan G. Osorio, Fernando J. Muzzio, Evaluation of resonant acoustic mixing performance, Powder Technology, Volume 278, 2015, Pages 46-56, ISSN 0032-5910, http://dx.doi.org/10.1016/j.powtec.2015.02.033.

256. Zahra Karami, Mehrdad Hamidi, Cubosomes: remarkable drug delivery potential, Drug Discovery Today, Volume 21, Issue 5, 2016, Pages 789-801, ISSN 1359-6446, http://dx.doi.org/10.1016/j.drudis.2016.01.004.

257. Jungil Park, Hyunwook Nam, Sun Young Ahn, Youngmi Kim Pak, James Jungho Pak, A reservoir-type oxygen sensor with $2 \times 3$ array for measuring cellular respiration levels, Sensors and Actuators B: Chemical, Volume 176, 2013, Pages 913-920, ISSN 0925-4005, http://dx.doi.org/10.1016/j.snb.2012.09.037. 